Portland State University

PDXScholar

Summer 7-30-2013

\title{
The View from the Table: An Analysis of Participant Reactions to Community-Based Dialogues on Food and Justice
}

Jennifer Turner

Portland State University

Follow this and additional works at: https://pdxscholar.library.pdx.edu/open_access_etds

Part of the Environmental Studies Commons, Other Food Science Commons, and the Urban Studies and Planning Commons

Let us know how access to this document benefits you.

\section{Recommended Citation}

Turner, Jennifer, "The View from the Table: An Analysis of Participant Reactions to Community-Based Dialogues on Food and Justice" (2013). Dissertations and Theses. Paper 1092.

https://doi.org/10.15760/etd.1092

This Thesis is brought to you for free and open access. It has been accepted for inclusion in Dissertations and Theses by an authorized administrator of PDXScholar. Please contact us if we can make this document more accessible: pdxscholar@pdx.edu. 
The View from the Table: An Analysis of Participant Reaction to Community-Based

Dialogues on Food and Justice

by

Jennifer Turner

A thesis submitted in partial fulfillment of the requirements for the degree of

Master in Urban Studies

Thesis Committee:

Nathan McClintock, Chair

Thaddeus Miller

Amy Lubitow

Portland State University

2013 


\begin{abstract}
While Portland, Oregon's sustainable food movement wins accolades for explicitly situating itself in opposition to the industrialized global food system, it often fails to address systems of oppression that are reproduced within the alternative agri-food movement itself. This demonstrated aversion towards the messy, complex, contingent nature of the social world reflects larger processes of "de-politicization" of the overall sustainability agenda, which leads to the favoring of technological and/or spatial solutions that may undermine the social equity and justice dimensions of the "triple bottom line." This thesis focuses on an action research project involving a series of community dialogues that provided participants with a common language and understanding necessary to interrogate issues of race and class in Portland's sustainable food movement while developing visions for possible futures. Dialogue participants may find new ways to communicate, learn, identify common goals and best practices, and potentially network, collaborate and/or co-produce transformative anti-oppression strategies that integrate into the sustainable food movement. By asking those vested in the sustainable food movement to interrogate dimensions of anti-oppression consciousness, the movement becomes fortified with voices better equipped to envision sustainability within a more political and contingent reality that recognizes conflicts of power, and less resembling an idyllic, utopian, and ultimately impossible sustainability. This thesis delivers some preliminary outcomes following the dialogue series by describing and reflecting on the series' implementation and processes, and reflecting on its impact on
\end{abstract}


participants' anti-oppression consciousness in the context of food and sustainability, while discussing possibilities for future scholarship. 


\section{TABLE OF CONTENTS}

ABSTRACT

LIST OF TABLES $\quad$ V

CHAPTER 1: BACKGROUND 1

CHAPTER 2: THEORETICAL FRAMEWORKS 6

Critical Studies of Sustainability $\quad 6$

Race, Class, and Food 13

Action Research for Social Change $\quad 20$

Linking Theory to Practice $\quad 22$

Research Goals and Questions 26

CHAPTER 3: DIALOGUE SERIES DESIGN 28

Dialogue Series Overview 28

Participants: Recruitment, Application \& Selection 29

Participants: Description 33

Dialogue Series Structure and Timeline 36

Curriculum 38

Participant Evaluation $\quad 40$

Data Sources and Collection 42

Data Coding $\quad 43$

Reflexivity as Researcher 46

CHAPTER 4: RESULTS \& DISCUSSION 49

Collaboration and Relationships $\quad 50$

Visions for Future Work

Introduction to New and Challenging Concepts 56

$\begin{array}{ll}\text { Wanting More } & 60\end{array}$

"Who isn't at this table?" Diversity and Representation 62

CHAPTER 5: IMPLICATIONS \& FUTURE DIRECTIONS 72

Critical Sustainability $\quad 72$

Race, Class, and Food

Action Research $\quad 75$

Possible Future Directions

CHAPTER 6: CONCLUSION

REFERENCES $\quad 83$

APPENDIX A: APPLICATION $\quad 89$

APPENDIX B: APPLICANT SELECTION CRITERIA 92

APPENDIX C: SOCIAL IDENTITY MAPPING BRAINSTORM 95

APPENDIX E: INTERRUPTIONS $101 \&$ SCENARIOS 97

APPENDIX F: KEY FOOD ISSUES 99 
APPENDIX G: MIDPOINT ONLINE EVALUATION

APPENDIX H: FINAL EVALUATION

APPENDIX I: APPLICATION OF CODES 


\section{LIST OF TABLES}

TABLE 1: DIALOGUE SERIES OVERVIEW

TABLE 2: REFERENCES REGARDING COLLABORATION AND RELATIONSHIPS

TABLE 3: REFERENCES REGARDING VISIONS FOR FUTURE WORK

TABLE 4: REFERENCES REGARDING NEW AND CHALLENGING CONCEPTS 57

TABLE 5: REFERENCES REGARDING WANTING MORE TIME, EDUCATION, DEPTH

TABLE 6: REFERENCES REGARDING CONCERN OVER DIVERSITY AND REPRESENTATION 


\section{CHAPTER 1: BACKGROUND}

With its abundant farmers markets, widespread availability of local, artisan products, prolific home and community gardening scene, flexible urban agriculture zoning, and a political climate characterized by progressive environmental policy, Portland, Oregon could be "foodie heaven." Portland's support for alternative, sustainable food networks situates the city's food-centric ethos in square opposition to the mainstream global agri-food system and its toxic impacts on the environment and public health (Guthman, 2003). But despite the city's demonstrated interest in alternatives to the industrial global food system, its sustainable food movement appears to be blind to instances of oppression potentially reproduced from within.

A few anecdotes illustrate this blindness, and suggest a profound need to more explicitly integrate a social justice lens to the city's alternative food agenda. First, during a Q\&A session following a community event in March 2012 organized by Portland State University and People's Food Co-op to promote the release of the Cultivating Food Justice reader (Alkon and Agyeman, 2011), the first statement from the audience was, "I'll say what I know we all are thinking... poor people are ignorant about good food." This comment unfortunately set the tone for an hour-long discussion dominated by calls for missionary-style strategies to educate what is assumed to be an otherwise disinterested, downtrodden low-income population about the virtues of eating well. Spoken to a room full of Portlanders interested in issues of food justice, this comment suggests a peculiar disconnect between the good intentions behind the vision of "good food for all," and the strategic thinking and action involved in implementing this vision. 
A few months following the People's Food Co-op event, the Multnomah Food Initiative, a multi-stakeholder county-level project to develop the Portland metropolitan region's food system visions and goals, held its third-annual Food Summit. The theme of the summit was "Growing Food Justice: Cultivating a Shared and Broad Understanding." Following a speech by Multnomah County Chair Jeff Cogen on Oregon's status as a second-hungriest state in the nation and the food-related disparities experienced by lowincome communities and communities of color, the over 300 summit participants attended sessions with titles like "Growing Food Justice in the Urban Farming Movement" and "Making Your Work Count: Measuring Food Justice, Winning Friends and Influencing People.” The Multnomah Food Initiative's summary of the event describes it as a moment of diversity and opportunity for furthering the region's food justice goals ("Summit Summary," 2012). While considered a success by its organizers, many attendees of the Summit critiqued its presentation of food justice, arguing that it was neither shared, nor broad. ${ }^{1}$ Issues of institutional and/or structural oppression were glossed over, with only minimal attention paid to topics relevant but ultimately peripheral to food justice, such as the spatial distribution of food deserts in the city.

One component of the Food Summit was the Portland-Multnomah Food Policy Council Food Justice Working Group's (FJWG) report-back on their recent food justice listening sessions. Earlier in 2012, the FJWG distilled a definition of "food justice" out of

\footnotetext{
${ }^{1}$ This claim is based on my observations during the Summit, specifically of Summit attendees speaking up during workshop sessions and roundtables to comment on the lack of direct engagement with issues of race and class in regards to food justice. This argument is also based on informal, personal conversations with unnamed Summit attendees who expressed frustration with the how the program "danced around" more sensitive topics of race and class.unnamed Summit attendees who expressed frustration with the how the program "danced around" more sensitive topics of race and class.
} 
several hours of community-based listening sessions, an important step in articulating a common vision of food justice in Portland that would guide future action. Yet the way in which the Summit program unveiled the outcome of the listening sessions suggests some hesitation on the part of its organizers to engage with the inherently race- and classsensitive nature of food justice. This definition, central to the Summit theme, was not publicized in any Summit materials, and the only attendees exposed to the definition were those who self-selected to attend a singular workshop dedicated to its release.

In short, it appears that while explicitly centered on food justice, the 2012 Food Summit failed to directly engage with the complex issues of race and class inherent to its theme. The 2012 Food Summit's emphasis on food justice illustrates how the city and county have emphatically ramped up their focus on food systems issues under the banner of social justice and equity, but the specific concepts and ideas that define food justice remain unclear. The Summit and FJWG outcomes outline the urgency to develop a shared understanding of what justice and equity might look like, and the need to identify the details of different and potentially more complex manifestations of injustice.

This underdeveloped ability to meaningfully engage with issues of oppression in the sustainable food movement is complicated, if not enhanced, by the city's specific adoption of an "equity lens" in the recent release of the Portland Plan, a multi-sector policy vision recently completed to guide the updated content of city's legally binding Comprehensive Plan. As the city has expressed an explicit interest in transitioning to more equity-based urban design, the ability to intentionally and meaningfully confront injustice and oppression becomes even more essential. 
As such Portland's food movement is characterized by its concerted efforts to cultivate a more sustainable, localized alternative to the global-industrial food system, but also by its demonstrated disconnect from the dynamics of social justice as they operate within these efforts. Portland's reputation as a "foodie haven" and beacon of sustainability becomes problematic in the absence of food justice. The product of this strained relationship between food systems activism and social justice is discordant approaches and strategies, and the potential to undermine the equity components central to this work. Without an explicit social justice lens, Portland's food movement may be troubled by colorblindness, ${ }^{2}$ patronizing missionary-style logics, and deep-seated class bias. As the Food Summit illustrates, Portland is laudably enthusiastic about engaging with food justice, but in order to be effective, targeted efforts are needed in order to resolve the disconnect between the city's agendas for sustainable food and social justice.

In order to forge the stakeholder relationships necessary for resolving this disconnect while providing a facilitated space for direct engagement with topics of oppression, the intellectual project described in this thesis focuses on the processes involved in the creation of a community-based dialogue series on anti-oppression theories and strategies, as they relate to Portland's work around food and social justice. By creating a platform for building trust and common language and understanding, food

\footnotetext{
2 "Colorblindness" might be interpreted as a positive term, in which the overt, Jim Crow-character of racism is dismissed and society presumably functions in a race-blind manner (Brown et al, 2003). But claims to colorblindness have a more insidious effect. By remaining "blind" to the subtle manifestation of racism, such as the disproportionate health and economic burdens experienced by people of color, covert and intangible forms of segregation and institutional/structural racism are allowed to persist because they are not easily identified and challenged (Bonilla-Silva, 2003).
} 
systems and social justice activists are given tools and relationships necessary for moving towards a just food system. 


\section{CHAPTER 2: THEORETICAL FRAMEWORKS}

Framing this study on the integration of more substantial social justice and antioppression lenses with Portland's sustainable food movement are three key theoretical frameworks: critical studies of sustainability; intersections of oppression, sustainable food, and food justice; and principles of community organizing and action research. Overlapping at times and divergent at others, these frameworks create the intellectual basis for this thesis' research goals and design. In this chapter, I first discuss the emergent tensions, consequences, and possibilities of sustainability in both theory and practice. In particular, I examine the dynamics of social sustainability, and how the pursuit of equity and social justice as a component of social sustainability is a complex, contingent process of contested visions and outcomes. Second, I describe how the sustainable food movement has been characterized as obscuring socially just outcomes, providing the basis for the food justice movement. Within this, I also explore some of the criticisms of the food justice movement's ability to effectively employ a cohesive anti-oppression framework, and how voices within the food justice literature have called for targeted efforts to build common understanding of social justice as a mechanism of the food system and movement. Finally, I discuss action research as an approach for supporting effective community organizing, and as a useful methodological lens for furthering community-driven, socially transformative goals. Together, these frameworks provide the theoretical rationale for this study and the methodological stance needed for its execution.

\section{Critical Studies of Sustainability}


Over the last few decades, the concept of sustainability as both a way of reconciling human impact on the biosphere (Rees, 1997) and a long-term vision for the use and conservation of resources so as to provide for current and future generations (WCED, 1987) has emerged as a cross-disciplinary driver for urban planning and policy. In 1987, the Brundtland Commission defined sustainable development broadly as "development that meets the needs of the present without compromising the ability of future generations to meet their own needs," (ibid). One common model for sustainability is that of the "triple bottom line" (Davidson, 2009), a tripartite vision that seeks to balance the mutual achievement of environmental, economic, and social sustainability.

Environmental and economic sustainability are fairly straightforward concepts, though not without their own sources of contention. In the most general sense, environmental sustainability advocates for consumption of natural resources mediated by an awareness of the needs of future generations, and a minimization of the ecological impact of that consumption. Economic sustainability advocates for economic efficiency in tandem with resource conservation and/or the development of an economic environment that can sustain in the long term. Visions of sustainable economic development are at times tied to concepts of "slow" or (less frequently) "no" economic growth, although a stable accumulation of capital is a rather common conceptualization of economic sustainability. In defining sustainability, there is also a distinction made between narratives of "thick" and "thin" sustainability. "Thin" sustainability seeks the "win-win" reconciliation of economic and ecological gains, whereas "thick" sustainability seeks more of transformative, ecologically restorative, and economically 
radical shifts (Vos, 2007). Social equity is a consideration but not central in visions of "thin" sustainability, whereas "thick" sustainability explicitly seeks the redistribution of harms and benefits inherent to equity and social justice (ibid).

The third component of the common tripartite vision of sustainability, social sustainability, is an abstract concept. While environmental and economic sustainability agendas often seek to stabilize and sustain current conditions, or to get more out of fewer resources, the broader goal of sustainability to meet the needs of the present generation without compromising those of future generations becomes complicated in the case of social sustainability. Social sustainability is often defined as social equity, although a clear theoretical understanding of social sustainability is still evolving (Vallance et al, 2011; Littig \& Griessler, 2005; referenced in Davidson, 2009). Also contained in the social sustainability framework are general concepts of human wellbeing, democratic governance, and democratic civil society (Magis \& Shinn, 2008). While achieving the balance and maintenance of the status quo is often thought of as a universally accepted goal for economic sustainability in particular, the social status quo may be unjust for some populations (Marcuse, 1998), potentially requiring radical change based on the needs of the community in question. The contemporary application of the sustainability agenda may be incompatible with the pursuit of social justice (Marcuse, 1998), as sustainability efforts in practice may obscure pre-existing inequities (Redclift, 2005). Sustainability projects are frequently criticized for either overstating their positive effect on equitable social outcomes, or outright ignoring these outcomes all together (Gunder, 2006). Projects promising positive economic and/or environmental yields may be 
considered a success with only cursory attention paid to, or even at the expense of, social equity outcomes, and "concerns with environmental and economic sustainability have eclipsed efforts to understand the social aspects of sustainability," (Dillard et al, 2008, p. 2). The recurrent favoring of economic and environmental sustainability agendas contradicts the perceived universally applicable benefit of sustainable development, which in theory appeals to the interests of not only current generations, but also future generations to come. To this end, sustainable development when defined as a tripartite balance is not broadly compelling if it does not actively and meaningfully promote socially equitable outcomes.

Illustrated by the tensions embedded in the application of a tripartite definition of sustainability, the social sustainability agenda contains contested visions of what an equitable society might look like, contested processes of developing these visions, and the situated reality of these visions in practice (Davidson, 2009). Because the discourse surrounding sustainability largely defines it as a broadly understood and accepted agenda that often defies reflexive political conflict (Miller, 2013), the contested realities behind the socially sustainable city become blurred. ${ }^{3}$ Sustainability is frequently characterized as a universally stable logic with a sense of urgency that transcends the messiness of cross-

\footnotetext{
${ }^{3}$ An important distinction to make is that of how universal discourses of sustainability are applied in specific places. While in this chapter I refer to universal sustainability discourses in terms of its broad narratives, it is crucial to recognize the contextual application of these universal discourses across different spatial and organizational scales. In Portland, various actors specific to the city (i.e. policymakers, organizational leads, community stakeholders) coalesce around the city's sustainability agenda, and set into action what sustainability looks like and how it operates that is specific to Portland. Sustainability as defined by these place-specific actors becomes a universal, uncontested vision. In the context of sustainable food, this situated application of a universal understanding is illustrated by the anecdote regarding the 2012 Food Summit, in which a food justice banner was held overhead, with the assumption that the summit's theme would resonate equally across populations. Indeed, the idyllic, universal definition of sustainability that exists in Portland may differ from what constitutes sustainability elsewhere in the US and on the globe, but what this critical sustainability framework argues is that across scales and contexts, universal conceptions of sustainability can be problematic.
} 
class, cross-cultural, and cross-territorial politics of difference (Swyngedouw, 2007; Lubitow \& Miller, forthcoming). The de-politicization of sustainability is a symptom of a broader tendency towards consensus-driven, conflict-averse governance that takes neoliberal capitalist systems as given and universally applicable (Swyngedouw, 2007). These are some of the characteristics of what some critical scholars refer to as "postpolitical" society, in which dissent towards this consensus-based vision of democratic governance is displaced, characterized as irrational, contrarian, and against the greater good (ibid; Mouffe, 2005; Allmendinger \& Haughton, 2012). As a conceptual alternative to harmonious post-political visions of democracy, "agonism" is defined as the processes of recognition of political conflict and difference, regarding this recognition of difference as a productive, necessary component of democratic society (Mouffe, 1999). The displacement of dissent and rejection of agonism apparent in the mainstream sustainability discourse introduces questions of the power dynamics implicit in a postpolitical sustainability: who defines the greater good, and who decides on - and ultimately benefits from - the solutions? Post-political visions of sustainability, defined by their aversion to conflicts of power and privilege, are typically aligned with spatial and technological solutions because of their promise for political neutrality, while overlooking the challenging - yet potentially transformative - task of directly engaging with social disparities and inequities (Lubitow \& Miller, forthcoming). While solutions designed to resolve issues of spatial distribution, such as the placement of farmers markets, or technological opportunity, such as bicycle infrastructure, are valuable, they must be imbued with and complemented by strategies that more explicitly confront social 
equity concerns. When sustainability becomes universalized through post-political emphasis on consensus and uncontroversial, politically accessible solutions, the possibility of alternative, radical approaches is diminished.

The conflicted nature of defining the socially sustainable city is revealed by the contested processes and visions outlined above. This makes the doing of social sustainability, contingent as it may be, an opportunity and challenge to assert social priorities to disengage from otherwise constrained visions of a universal sustainability that seek a mythic state of ecological and economic harmony (ibid, Swyngedouw, 2007). Agonistic politics are fundamental for realizing the myriad possibilities for sustainability. In a critical, agonistic sustainability, technological and/or spatial solutions may be effectively informed by the potentially slow, difficult work of engaging with politics, allowing these solutions to better mirror the values of justice and equity embedded in the social sustainability discourse. Additionally, by embracing a more critical sustainability that interrogates the dynamics of power and privilege that may be culpable in creating a socially unsustainable world, solutions that fall outside of the boundaries of technology have the opportunity to emerge.

In an attempt to reconcile these social and political tensions in sustainability work, the just sustainability framework explicitly connects concepts of social justice to sustainability in practice (Agyeman, 2005). This framework draws on the intersecting interests of the environmental justice movement and sustainable development. Because of its explicit integration of the grassroots, bottom-up nature of the environmental justice movement, just sustainability departs from traditional sustainable development, which is 
typically characterized as top-down and government/NGO-driven. Just sustainability is defined as "a better quality of life for all, now and into the future, in a just and equitable manner, while living within the limits of supporting ecosystems" (Agyeman, 2005, p. 79). By merging sustainable development with social justice, Agyeman's framework begins to scratch the surface of post-political sustainability's veneer. But in order to really interrogate how social justice and sustainability interact, a deeper understanding of justice is needed.

Identifying justice is a complex task, as forms of (in)justice can be visible and easily recognized, or they can be elusive, obscure, and contingent. Despite this complexity, justice is most commonly conceptualized as the disparate distribution of harms, impacts, benefits, and burdens across populations (Walker, 2009). This is a limited view of the multiple and nuanced ways that injustice can manifest. For this reason, efforts to promote equity and thus resolve injustices must be willing to acknowledge a potential plurality of interactions between wellbeing, vulnerability, and justice (ibid). Understanding multiple possible forms of injustice is necessary as particular claims to (in)justice are capable of producing normative assumptions and evaluations of optimal social, political, economic, and environmental conditions, potentially foreclosing on the recognition and evaluation of alternate forms of injustice. By limiting the definition of justice to a simple, singular possibility, less visible — and potentially more complex — conditions of injustice may be overlooked. Walker (2009) proposes a network of diverse justice frameworks that permit analysis of the underlying conditions that might work to create inequitable outcomes. 
Walker proposes a framework of justices that permit analysis of the underlying conditions that might work to produce inequitable outcomes. In addition to the aforementioned justice of distribution, he outlines justice of recognition, and justice of procedure and participation. Justice of recognition is defined as the production of spaces of respect, value, and support, and that "at the core of misrecognition are cultural and institutional processes of disrespect, denigration, insult, and stigmatization, which devalue some people in comparison to others," (Walker, 2009, p. 626). In the production of injustice of recognition, a devaluation of people becomes tangled in the devaluation and stigmatization of place. Injustice of recognition may also occur as people move in and out of environments in which they are culturally disconnected and may experience a lack of belonging. Justices of procedure and participation, on the other hand, describe access to decision-making as a "spatiality" of justice, in that enabling democratic process suggests "access to spaces, and flows between spaces, that have previously been restricted," (2009, p. 627). Lack of procedural justice is "intimately wrapped up with a closed geography of information, access, and power" and 'procedural fairness' that includes the fluid movement of people, ideas, and perspectives "across the boundaries of institutions and between differentiated elite and lay spaces," (ibid). Justices of procedure and participation facilitate the collaboration of cross-cultural, cross-discipline, and crossinterest knowledge and decision-making. Having the relevant literacy and access to adequate translation is a significant component of procedural fairness and justice of participation.

Race, Class, and Food 
It is with this understanding of the tensions deeply tangled in the sustainability discourse, enhanced by Walker's more nuanced framework for conceptualizing justice as we move towards more critical visions of sustainability, that I now turn to the application of these concepts in the context of sustainable food. An exploration of the forms of oppression that emerge in the food movement reveals many contradictions and tensions within the increasingly popular movement towards bettering the food system, and lays the foundation for the food justice movement.

The sustainable food movement, popularized by public figures like Michael Pollan and Alice Waters, is a form of resistance to a global-industrial food system responsible for environmental degradation, the proliferation of cheap, unhealthy food, and disproportionate power in the hands of a select few corporations (Feenstra, 1997; Kloppenburg et al, 1996). In an attempt to de-centralize the food system, the food movement maintains deeply guarded values surrounding food production and consumption, such as organic agriculture, local food economies, home and community gardening, and the value of certain diets (i.e. vegetarian/vegan). Because of the way that these values dominate the social and cultural foundations of the sustainable food movement, Walker's concept of misrecognition is apparent in the subtle ignorance towards cultural, historical, and socio-economic contingencies that inform how individuals across race and class boundaries interact with the food system.

As with broader sustainability efforts, what constitutes a sustainable food system is often regarded as universally accepted and apolitical, while social and political tensions remain overlooked (Hinrichs, 2003; DuPuis \& Goodman, 2005). While well intentioned, 
sustainable food as resistance creates powerful dichotomies between the alternative and the mainstream, the virtuous and the destructive. The former is seen as slow, intimate, and intentional, and the latter is seen as fast, consumptive, and impulsive (Guthman, 2003). The result of this characterization is a food movement whose central values are seen as ultimately more valuable and rarified than those of the mainstream. This hierarchy is complicated by how the sustainable food movement is typically most resonant with a privileged white, middle-class population who engage with sustainable food largely as consumers and not activists (Slocum, 2007; Alkon \& Agyeman, 2011; Guthman, 2008b; Johnston \& Szabo, 2010).

While the sustainable food movement seeks positive recourse from the globalindustrial food system, the movement is not without criticism. The ethos of the sustainable food movement often establishes a dichotomous context of good versus bad, and has been described as an elitist, inaccessible social movement, in which the preferences and values of a privileged population are elevated and then normalized as the "right" way to engage with the food system (Slocum, 2006; Alkon \& Agyeman, 2011; Guthman, 2008a). The food movement has been accused of colorblindness, in that the dominant cultural values of whiteness remain unquestioned (Slocum, 2006; Guthman, 2008a), and the spaces in which this movement occurs, such as farmers markets, become coded with a specific set of racialized values, producing a exclusionary "chilling effect" on people of color (Guthman, 2008a; Slocum, 2007; Alkon, 2012). Similarly, the alternative food movement has been critiqued for its missionary-style approach for "bringing good food to others" (Guthman, 2008b), in which the situated, culturally- 
specific food knowledge shared by communities of color is ignored in favor of the implementation of a particular set of "whitened" solutions. Imbued in this missionarystyle approach are certain privileged values, such as agrarianism as a romanticized view of "getting one's hands dirty" (Allen, 2004; Carlisle, 2013), as well as the belief that the "back to the soil" nature of organic, natural foods leads to an inherent possession of virtue (Guthman, 2003). Also questioned are perceptions of inherent virtue of the local food movement (DuPuis \& Goodman, 2005; Hinrichs, 2003), which is often cited as an appropriate mechanism for strengthening the bond between farms and consumers. Despite their appeal to community-level change and distancing from the corporate-driven food system, without an explicit social justice framework, local food movements risk reproducing inequities found at the global scale (DuPuis \& Goodman, 2005; Allen, 2008). Through these processes of unreflexive valorization, the local food economy and agrarianism begin to reflect the geographic imagery of whiteness, which is characterized as "good, proximate, wholesome, and local" (Slocum, 2007, p. 527), while undermining possible representations of communities of color, and low-income communities.

Embedded in the local and sustainable food discourses are consumer slogans like "buy local" and "vote with your fork," and consumption-oriented strategies like the development of farmers markets, where consumers can practice connection to the food system through spending. The values of the consumer citizen have become embedded in the food movement, in which purchasing and consumption are seen as public acts of citizenship (Lockie, 2008). The food movement's emphasis on individual consumer choice and other market-based solutions as the primary mechanisms for effecting 
systemic change is criticized for lacking the social and political dimensions necessary for just and equitable outcomes (DeLind, 2002; DuPuis \& Goodman, 2005; Guthman, 2003). Additionally, the emphasis on public, politically engaged consumption reflects a culturally specific approach to food system reform, one that demands centrality and attention, while potentially concealing the desire to simply shop with anonymity (Guthman, 2008b). Embedded in the concept of the individual citizen-consumer is the trope of personal responsibility, focusing on the individual choice to engage in healthy, sustainable eating habits, which effectively obscures the structural and institutional factors that contribute to negative food- and diet-related outcomes (Slocum, 2006; Allen, 2004; Guthman, 2011). Efforts to imbue the sustainable food movement with a social justice lens are critiqued along similar lines, specifically for their frequent reliance on market- or consumption-oriented solutions that contradict the overarching demand for community-oriented systemic change (Alkon \& Mares, 2012).

According to food justice scholar Patricia Allen, "our food system does not meet the fundamental criteria of social justice such as freedom from want, freedom from oppression, and access to equal opportunity" (2008, p. 158). This critique is heightened when one considers how the conventional food system evolved and survives today on the basis of profoundly oppressive institutions (Slocum, 2006). For example, processes of institutionalized segregation in African-American communities like "supermarket redlining," or the closure of urban grocery stores in favor of relocation to more affluent suburbs, have historically contributed to the uneven spatial distribution of retail food outlets (Eishenhauer, 2001; McClintock, 2011). The benefits and harms of the food 
system are not distributed evenly across dimensions of race and class, nor are they distributed evenly across urban space, as the disproportionate concentration of fast food in black urban neighborhoods illustrates (Block et al, 2004). As these examples suggest, the pervasive colorblindness and reflection of dominant white values in the sustainable food movement described above may effectively overlook the race- and class-based harms of the food system, despite the profoundly disproportionate impact of the food system on people of color (Slocum, 2006).

Other forms of injustice may be obscured by the sustainable food movement's frequent embodiment of race and class privilege. As the People's Co-op anecdote illustrates, one common assumption in the sustainable food movement is that those who engage with the conventional food system simply lack the knowledge or taste to eat good food, and that through education, a behavior shift will naturally occur (Guthman, 2008b). This assumption implies that alternative food activists possess a specific and enlightened understanding of food and eating, and that behavior complicit with the conventional food system lacks this enlightenment. This enlightenment contributes to an oppressive form of "healthism," in which the embodiment of healthy or "perfect" eating becomes conflated with expressions of virtue, value, and citizenship (Cheek, 2008; LeBesco, 2011; Guthman, 2011). Those who deviate from this perfect embodiment of health, through dietary choices or body size, may be perceived as weak, uneducated, or undeserving (Guthman, 2009; Evans, 2006; Saguy \& Riley, 2005).

If slow, organic, "good" foods are going to serve as alternative approaches to the food system, then they must also reflect values alternative to the harms identified within 
the mainstream food system (Guthman, 2003). Despite its good intentions, the alternative food movement's lack of emphasis on personal and institutional bias, anti-racist practice, and social justice limits its ability to effect such change (Slocum, 2006; Sbicca, 2012). Anti-oppression in practice can serve as a mechanism for cross-difference alliances crucial for in working towards sustainable, community-driven food systems (Slocum, 2006). In an attempt to forge these cross-difference alliances and more effectively ground sustainable food systems in social justice and anti-oppression frameworks, the food justice movement emerged as a bridge between activism and theory (Alkon \& Norgaard, 2009; Gottlieb \& Joshi, 2010). The food justice movement contends that access to food on one's own individually- and culturally-specific terms is a human right, and seeks the provision of food while "imagining new ecological and social relationships," (Alkon \& Agyeman, 2011, p. 5). The food justice movement advocates de-linking access to good food from the monocultural visions that have led to charges of elitism in the sustainable, organic food movement by recognizing the dynamics of power that exist within (Alkon \& Agyeman, 2011), and interpreting efforts to reform the food system through an antioppression lens. Consequently, the food justice movement's liberatory motivation "sacrifices its resonance" (Sbicca, 2012, p. 456) with the traditional sustainable food movement's aesthetic of uncritical gustatory pleasure and empowerment of the individual consumer, and favors community-based emancipatory action and social justice.

The food justice movement is still coalescing as a uniform social movement and its relatively abstract form contributes to potential competing visions of how to put food justice into practice (Gottlieb \& Joshi, 2010; Sbicca, 2012). As a movement still in search 
of its social justice footing, food justice is challenged by the need to establish common ideological and theoretical understanding of anti-oppression theory that may then be mobilized in place (Sbicca, 2012). It is also challenged by the need to recognize the nuance and plurality of injustice outlined by Walker, and to expand on the conviction that technical and spatial strategies (i.e. inserting grocery stores into food deserts) that many food justice activists advocate are the silver bullet for resolving the injustices of the food system. Despite espousing a necessary and powerful social justice logic, the food justice movement at times suffers from tensions between discussion and action; that is, a "gap between intent and outcome" (Allen, 2008, p. 159).

\section{Action Research for Social Change}

Resolving the tension between discussion and action found within the food justice movement requires effectively building community within the movement itself. The processes of honing relationships and collaboration around identified issues inherent to community organizing are a central component of effective social movements (Stall \& Stoecker, 1998). A well-organized community is both abstract and potent, as communities are increasingly seen as powerful stakeholders capable of effecting significant corporate or policy change (Berry, 2003). Community organizing is often thought of as the "pre-political" 4 precursor for any social movement to take roots (Stall \& Stoecker, 1998). This implies that there is something meaningful and organic about the relationships and trust that emerge in an effectively organized community. An emphasis

\footnotetext{
${ }^{4}$ The concept of "pre-political" is distinct from the post-political critical framework described earlier in this chapter. In the context of community organizing, "pre-political" is used to refer to that which lays the groundwork for politically motivated social movements (Stall \& Stoecker, 1998).
} 
on empathy, trust, and building cross-difference relationships is central to Aigner et al's (2002) concept of "whole community organizing." While community organizing is a contextual practice rooted in situated knowledge and may therefore exist differently across communities (Stall \& Stoecker, 1998), the processes can be slow, deep, and personal (Aigner et al, 2002). Hustedde and Ganowicz describe community development in similar terms, as "a process of creating or increasing solidarity and agency" (2002, p. 3) within the community.

Complementing the important relational elements of community organizing, action research is a relational methodological framework. Broadly, action research is a resistance to the detached, objective science that has historically produced social injustice (Reason \& Bradbury, 2008, p. 19). In action research, inquiry is framed as 'doing with' rather than 'doing for' its participants (Greenwood \& Levin, 2007, p. 1). Like processes of community organizing, successful action research hinges on a collaborative process of sharing knowledge, ideas, best practices, and visions. Unlike traditional forms of research, in which the researcher takes great care not to inform the outcomes of the study, action research is transformative, seeking social impact at the same time as the production of knowledge (McTaggart, 1994; Reason \& Bradbury, 2008). The socially transformative researcher "must be in the action, be finite and dirty, not transcendent and clean” (Haraway, 1997, p. 36, cited in Clarke, 2005, p. 74). Both the researcher and participant are valued in the production of knowledge and the resolution of social problems, and the researcher is not regarded as a privileged source of expert knowledge (Greenwood \& Levin, 2007). In this regard, action research is a mechanism for inclusive, 
transparent knowledge production and problem solving, which recognize the complexity of the social environments containing the problems at hand.

Action research values a diversity of perspectives, experiences, and histories. For this reason, it does not ask that the researcher "become one with" (Greenwood \& Levin, 2007, p. 54) the community in which the research project is situated. Rather, the reflexive perspective of the researcher is a valued component of action research (Moore, 2004). Rather than asking the researcher to take great care not to inscribe the research project with his or her subjectivity, in an action research project, the diversity of experiences and perspectives, including that of the researcher, is viewed as an opportunity to enrich the knowledge produced (Greenwood \& Levin, 2007). Importantly, the action research project seeks change-oriented social knowledge, and its credibility is verified through the production and testing of knowledge in practice (ibid). The action research project is based on the formation of situated knowledge meant to solve local, contextual problems as articulated by the researcher and participants. Methodologically, the action research project does not follow a strict, pre-prescribed outline of appropriate tools and techniques; it is not an inherently qualitative or quantitative approach, but rather one based on values of reflexivity, diversity, and participation (ibid; McTaggart, 1994).

\section{Linking Theory to Practice}

Food serves as a powerful conceptual location for the examination of dynamics of race and class as they operate in society (Slocum, 2010). Food is both a profound expression of cultural identity, and a tool for the assertion of cultural privilege and hierarchy. As described above, sustainable food movements may illustrate the norms of 
whiteness in practice, but their potential for the creation of more progressive politics across difference must not be ignored (ibid). The social justice framework underpinning the food justice movement - as well as the critiques of the movement's application of social justice in practice - provides a useful point of analysis for strengthening the application of social justice in sustainability work as a whole. In addition to challenging the food movement to better embody the social justice agenda that the food justice movement espouses, how can food justice better integrate the radical lens it strives for but may lack in practice? Focusing an anti-oppression lens on food justice work is theoretically intuitive, but the actual embodiment of anti-oppression practice does not occur automatically. As the events of the 2012 Food Summit illustrate, an anti-racist, anti-classist perspective should not be taken as given when organizing around food justice.

Participatory, communicative strategies to "effectively bridge the gap between different notions of food justice" (Sbicca, 2012, n.p.) serve as conduits for the operationalization of anti-oppression consciousness in the food movement. Sbicca calls for the creation of space for activists and stakeholders to hone in on the potentially divergent concepts of oppression as they relate to food justice for the movement to coalesce on common ground. Because my research focuses on the creation of common ground among stakeholders, in addition to asking participants to co-create visions of possible futures, this project intends to create just that space through the creation of a series of community-based dialogues on oppression, power, privilege, and the food movement. The project captured in this thesis relies upon the relational approach to 
community organizing described above, as taking the time and care to build meaningful relationships is key for establishing the common language and mutual understanding needed for the application of an anti-oppression lens in food systems work.

Allen (2008) points out that because of its relevancy in the lived experience of every person, the food system is "a perfect vehicle for doing public sociology and for applying sociological knowledge and heuristics," (p. 159). The immediacy of food in lived experience and its relevancy as a site for exploring the political dynamics of social sustainability makes it an opportune subject of action research. Food provides an opportunity for potent knowledge about the social world to be produced. As a researcher, I am also in the unique position to inform this production of knowledge. To this end, Allen (ibid) specifically argues for the implementation of action research projects that "engage real people in their real lives" (p. 160) as a mechanism for merging social justice and sustainable food.

The dialogue series described in this thesis is in direct response to Allen's call, and the action research lens described above provides the means for accomplishing this. Because Portland's food movement is celebrated for its commitment to sustainable practices and outcomes, yet its lack of preparedness in confronting issues of social justice illustrates a potential absence of an essential equity component in its outcomes, this thesis is also in response to the aforementioned observation that social justice and equity are often ignored and potentially troubled concepts in sustainability work, and that this is readily apparent in the sustainable food movement. Food systems are a significant component of the overall sustainability agenda (Feenstra, 2002; Alkon \& Agyeman, 
2011), and provide a useful lens for exploring potential avenues for reconciling the tensions surrounding equity and sustainability.

To this end, the creation of the community-based dialogue series provides an opportunity to examine how stakeholders in Portland's sustainable food movement might effectively engage with concepts of anti-oppression and social justice, thereby imbuing both the sustainable food movement and overall sustainability discourse with a politicization of power and privilege that may be more conducive to socially equitable outcomes. The facilitation of dialogue as action research is based on the argument that in order to build a more sustainable food system, we must expand upon spatial and technical solutions, and integrate an analysis of the distribution of power and privilege and how these dynamics operate in a sustainable and just system. By asking those vested in the sustainable food movement to interrogate dimensions of anti-oppression consciousness, the movement becomes fortified with voices better equipped to envision sustainability within a more political and contingent reality that recognizes conflicts of power, and less resembling an idyllic, utopian, and ultimately impossible sustainability. The dialogue series described here should therefore build capacity within Portland's food movement to execute contextually situated visions that envision solutions to complex social problems.

Through the facilitated opportunity to delve deeper into topics of oppression as they manifest in the supposedly apolitical work of sustainable food, participants in this dialogue series were exposed to the plurality of justices outlined by Walker, and asked to consider how this plurality operates within the sustainable food movement in complex ways. Participants were encouraged envision outcomes that capture this nuance, and will 
ideally draw upon their experiences in the dialogue series more readily when working on the ground in the future. In an effort to better understand the merging of social justice, sustainable food, and food justice, this thesis focuses on the creation and execution of the community dialogue series on food and oppression, as well some experiences and outcomes from the series as expressed by its participants.

\section{Research Goals and Questions}

Overall, the intent of the action research project described here is to induce transformative social outcomes through a dynamic, participatory dialogue series composed of workshop sessions that provided participants with the opportunity learn, reflect, collaborate, and co-produce their afterlife. More specifically, the primary goal of this thesis is to hone in on the processes involved in embedding an anti-oppression consciousness into participants' understandings of sustainable food, and to reflect on the challenges and opportunities that appear in this kind of facilitated process. Additionally, this project establishes and tests a model for facilitated dialogue that relies on crucial university-community relationships and engagement that may be replicated both in Portland and elsewhere (Hartley \& Harkavy, 2010), and assesses some of the benefits and limitations of this model.

Determining the extent to which these research goals are achieved involves an understanding of the outcomes produced by the dialogue series from the perspective of its participants. In order to provide adequate discussion of the series' outcomes, challenges, and successes, the primary basis for my analysis is the participants' evaluative reflections on their experiences with the dialogue series, supported by my own observations as a 
participant-researcher. By exploring how participants reflect on their experiences, I am able to determine ways in which the dialogue series was effective in facilitating the necessary development of common language and understanding surrounding the operation of oppression in the context of food, as well as the challenges and tensions involved in interrogating systems of oppression through a sustainable food lens. There are a few key questions scaffolding the analysis presented in this thesis: What do participant reflections on the dialogue series tell us about its impact and implications? What are the limitations, barriers, and challenges involved in creating a platform of this kind for merging social justice and sustainable food? Ultimately, what can we learn from this attempt to facilitate learning around consciousness of power, privilege, and difference in the context of sustainable food? 


\section{CHAPTER 3: DIALOGUE SERIES DESIGN}

The genesis, development, and execution of the Food Justice Dialogues series relied on the collaborative support of its project management team, consisting of myself, fellow MUS student Alex Novie, Master of Public Health student Monica Cuneo, PSU faculty principal investigator Dr. Nathan McClintock, and PSU faculty and dialogue series facilitator Sally Eck. This project was also generously supported through funding from PSU's Institute for Sustainable Solutions (ISS). This study received Human Subjects Research Review Committee approval on October 31, 2013 (HSRRC Proposal $\# 122362)$.

In this chapter, I will first provide a general overview of the series as a whole, and a brief discussion of my role as a reflexive researcher. I will then describe the design, curricular content, and evaluation of the dialogue series, paying particular attention to the processes involved in recruiting, vetting, and selection the participants, the curriculum design and flow, and how participants were asked to evaluate their experience. I will also describe the various data sources and the coding processes on which my analysis is based.

\section{Dialogue Series Overview}

To achieve the project goals, each workshop session was designed to assist its participants in the processes of unpacking issues of race, class, and other identity constructs in the context of food systems issues. The workshops also encouraged participants to articulate visions of possible solutions and strategies for the development of a flourishing food justice movement in Portland. Participants were asked to engage in 
reflexive thinking about their position as advocates for systemic food system change in Portland, as well as their personal and professional interaction with broader social, political, and economic forces.

\section{Participants: Recruitment, Application \& Selection}

Given the dynamic, participatory nature of this research, a major component of its coordination involved determining who would participate in the dialogues. The individuals participating in this project would not only set the tone for the conversations that took place, but also inform how the series' content would ebb and flow based on the needs of the group, and drive the collaborative, co-productive elements of the series' afterlife. ${ }^{5}$ Through the creation of a participant mix with a diversity of perspectives, experiences, and demographics, the dialogue project was able to attempt to bridge both the concepts behind and the application of social justice and food systems work. We also sought a diverse participant mix in order to encourage exposure to new perspectives, as well as the development of cross-interest and cross-organizational relationships. Through this intentional assembly of participants, those attending the dialogue series were able to connect with other stakeholders in the food and social justice fields in ways that were not necessarily available independent of this research. As I will discuss with more depth later

\footnotetext{
${ }^{5}$ Because the project management team was solely responsible for the solicitation and evaluation of participant applications, as well as the articulation of the broader research agenda, this research project does not readily align with a typical definition of "participatory action research" or PAR (Kindon et al, 2007; Moore, 2004). Orthodox definitions of PAR are community-driven in nature, in which community members, often of marginalized populations, define the research questions and approach, while the researcher(s) occupy a less central role in the fulfillment of research goals designed to achieve socially beneficial outcomes (Kindon et al, 2007; Travers, 1997). While the dialogue series described in this thesis strongly emphasizes an iterative, participatory structure, as well as the project's socially transformative capacity, this is a methodologically essential distinction to make.
} 
in this thesis, these cross-alliance connections play an important role in the consideration of how to move the overall sustainability agenda forward.

In order to create a participant group that represented a diverse array of interests, experience, and organizations, an online application was created and disseminated across several food systems and social justice online networks (e.g. COMFOOD listserv, Food For Oregon listserv, Portland State Urban Studies and Public Health departmental listservs), with the request that recipients forward the application to anyone that they felt might be interested in participating. The online application was housed at the ISS website, ${ }^{6}$ and consisted of questions designed to gauge the applicant's familiarity with food systems and/or social justice issues, his or her experience working with diverse viewpoints, and his or her experience with anti-oppression frameworks ${ }^{7}$. We asked applications to respond with information about age, gender identity, racial identity, primary language spoken, organizational and/or professional affiliation, and schedule availability. For the sake of building trust among the participant group and ensuring consistent attendance, we also asked applicants about their ability to commit to attending at least 7 out of the 8 total sessions. Applications were available for completion online between November 28 and December 14, 2012. There appeared to be broad interest in the dialogue series; for example, we received a number of inquiries from individuals outside of Portland who wanted to attend via Skype or through some kind of webinar. At the conclusion of the application period, over 150 individuals initiated the application

\footnotetext{
${ }^{6} \mathrm{http}: / /$ www.pdx.edu/sustainability/community-dialogues-on-food-justice-who-is-at-the-table

${ }^{7}$ For a full list of participant application questions, see Appendix A
} 
process, with a total of 46 completed applications received, and an additional 36 partial or withdrawn applications submitted.

The total number of workshop participants was set at a maximum of 20 people, with the expectation that the final number of participants would be lower. The number of participants was capped in order to form a group that would be conducive to discussion in both small and large group formats, was small enough to encourage informal conversation and the formation of relationships and trust, while large enough to ensure that multiple perspectives would be represented within the group. In order to assemble a group that best represented a diversity of demographic categories such as age, racial and gender identity, as well as the participant's level of expertise and experience in food systems and/or social justice work, and familiarity with anti-oppression frameworks, selection criteria based on each of these categories was used in the process of vetting applicants (for a full description of selection criteria, see Appendix B) The applicant selection process began with the project co-managers individually ranking each applicant according to the aforementioned selection criteria. After ranking each applicant individually, the top 30 applicants were reviewed and re-ranked by the project management team with the specific goal of ensuring a diversity of experience, background, and affiliation. For example, two applicants work for the Oregon Food Bank and while both were high-ranking after the individual application reviews, one was replaced with an applicant with a lower overall ranking, but different organizational affiliation during the group application review. 
Indeed, applicant selection was in many ways an intuitive process and grounded in an attempt to assemble a group that presented opportunities for both collaborative dialogue and constructive disagreement. In this sense, the other project managers and I had to rely on our interpretation of language and our "gut reactions" to the applications in determining the subtle characteristics of the applicant that could potentially help or hinder collaborative dialogue. For example, we engaged in a collaborative discussion on whether or not to invite applicants who appeared to be single-minded about their professional goals for attending, and whether or not these applicants would be willing to engage in more broadly theoretical discussions. Two applicants were rejected on this or similar ground. This more intuitive participant selection process demonstrates the importance of taking a reflexive stance as researchers in a community-oriented action research project. Finalizing the participant mix based on our interpretations of an applicant's language and our ability to "read into" an applicant's character was certainly fuzzy at best, and the final participant mix must be recognized as the output of the project managers' situated, subjective perspectives on the applicants and themselves. This aspect of creating the participant group also meant interrogating our assumptions of expertise, and we were concerned with questions of how a just food system is defined, how food systems expertise could be beneficial or problematic in a transformative dialogue, and how non-expert voices might play a uniquely essential role.

Illustrating the fuzzier side of the selection process is our collaborative discussion of whether or not to invite applicants who appeared to be single-minded about their professional goals for attending, and whether or not these applicants would be willing to 
engage in more broadly theoretical discussions. Two applicants were rejected on this or similar grounds. This more intuitive participant selection process illustrates the importance of taking a reflexive stance as researchers in a community-oriented action research project. Finalizing the participant mix based on interpretations of language and our ability to really know an applicant's character was certainly limited at best, and the final participant groups must be recognized as the output of the project managers' situated, subjective perspectives on the applicants themselves.

Following the selection process, an invitation to participate was sent to 20 applicants, of which 18 accepted; two participants declined shortly before the first session due to scheduling constraints. Because the withdrawals occurred shortly before the first session, and because the slightly smaller group would still be conducive to meaningful dialogue, we decided not to invite two additional applicants from the waitlist. By the final session, a total of 13 participants remained. The attrition rate was due largely to unforeseen schedule conflicts and attendance (i.e. missing more than one session).

A stipend was provided to participants who fulfilled their commitment to attend at least 7 out of 8 sessions, as defined in the application process. This stipend was not publicized in the application itself, as the budget required to provide the stipend had not been finalized until after the application phase of the project. The stipend, in the form of a Visa gift card, amounted to $\$ 200$ for those who attended all 8 sessions, and those who attended 7 received $\$ 175$.

\section{Participants: Description}


The individuals we selected to participate in the dialogue series represented a variety of organizations, experiences, and perspectives. In terms of racial identity, two of the participants identified as Latina and Hispanic, one of the participants identified as Asian-American (Vietnamese), and one of the participants identified as Native American. Of the participants attending the first session, three were men (including two co-project managers). The majority of participants were female and white, largely reflecting the demographic breakdown of the total applicant pool. The ages represented in the participant mix ranged from 24 to 68 .

It was important to ensure that the participant group represented a balance between professional and experiential history, and their degree of familiarity with food systems issues. Ensuring a diversity of applied experience and "on the ground" perspective would contribute to the transformative outcomes that we sought. For this reason, the participants represented a range of organizations and interests in the community. Included among the organizations represented were:

- Oregon Food Bank, the state's leading emergency food provider. OFB is committed to "eliminating hunger and its root causes" (Oregon Food Bank, “About Us," n.d.)

- Growing Gardens, a non-profit anti-hunger organization that helps low-income individuals and families around Portland develop and maintain food-bearing gardens (Growing Gardens, “About Us,” n.d.).

- Adelante Mujeres, a non-profit organization dedicated to the empowerment of Washington County's Latina community, specifically women. Among Adelante 
Mujeres' programs is Adelante Agricultura, a sustainable/organic agriculture program for Latino/a farmers (Adelante Mujeres, "Programs Overview," n.d.).

- Kitchen Commons, a non-profit project of the Northeast Coalition of Neighborhoods that provides kitchen and cooking resources necessary for community empowerment, affordable nutrition, and food justice (Kitchen Commons, “About Us,” n.d.)

- Urban Gleaners, a hunger-relief non-profit organization dedicated to the acquisition and redistribution of surplus food from restaurants, grocery stores, and other outlets (Urban Gleaners, “About Us,” n.d.)

- East Portland Action Plan, the collective organizational committees supporting the city of Portland's efforts to develop and improve East Portland (East Portland Action Plan, "Committees and Representatives," n.d.)

- Portland Public Schools, the city of Portland's school district.

Also among the participants were students, including one PSU senior and one PSU graduate student in the Leadership for Sustainability Education program. Also among the participants were several individuals with no explicit organizational affiliation, but may have perhaps had past volunteer experience or simply a stated interest in issues of food and/or social justice.

Overall, the participant group was selected with the pursuit of meaningful dialogue in mind. Many of the participants reflected on personal histories with food and oppression in their applications. These reflections suggested that while on the surface the participant 
group primarily identified as white women, the group contained a potent diversity of perspective, experience, values, and history.

\section{Dialogue Series Structure and Timeline}

While the nascent planning stages for the dialogue series began in Spring 2012, the bulk curriculum and logistics planning took place during the Fall 2012 term. The eight sessions of the series occurred over Winter 2013 term on Tuesday mornings from 9 to 11 a.m. in the Portland State University Urban Studies Building, Room 220. The series began on January 22, 2013 and concluded on March 12, 2013.

Table 1 provides an overview of the series structure and timeline, and describes each session's curricular goal, activities, and its broad desired outcome. In the following section on Curriculum, I will provide a more in-depth discussion of the rationale informing the curriculum and desired outcomes, as well as a breakdown of specific exercises, including Social Identity Mapping and Concept Mapping: Food in Portland.

Table 1: Dialogue Series Overview

\begin{tabular}{|l|l|l|}
\hline Session Number \& Date & \multicolumn{1}{|c|}{ Session Content } & \multicolumn{1}{c|}{ Intended Outcome } \\
\hline 1: January 22, 2013 & $\begin{array}{l}\text { Check-In: Introductions } \\
\text { Brainstorm: What is oppression? }\end{array}$ & $\begin{array}{l}\text { Building common language and } \\
\text { understanding of anti-oppression. }\end{array}$ \\
\hline 2: January 29, 2013 & $\begin{array}{l}\text { Check-In: Cultural Identity Poems } \\
\text { Brainstorm: Co-creating an ideal } \\
\text { learning community } \\
\text { Social Identity Mapping }\end{array}$ & $\begin{array}{l}\text { Co-creating the shared learning } \\
\text { environment. Building a common } \\
\text { language and understanding of } \\
\text { anti-oppression work. }\end{array}$ \\
\hline 3: February 5, 2013 & $\begin{array}{l}\text { Interrupting Oppression } \\
\text { Brainstorm: Why Interrupt? } \\
\text { Interruptions Practice: Food-specific } \\
\text { scenarios }\end{array}$ & $\begin{array}{l}\text { Identifying and interrupting } \\
\text { oppression. }\end{array}$ \\
\hline 4: February 12, 2013 & $\begin{array}{l}\text { Check-In: Reviewing Interruptions } \\
\text { More Dialogue on Interruptions }\end{array}$ & $\begin{array}{l}\text { Identifying and interrupting } \\
\text { oppression. }\end{array}$ \\
\hline 5: February 19, 2013 & Concept Mapping: Food in Portland & $\begin{array}{l}\text { Conceptualizing and envisioning } \\
\text { Portland's food environment. }\end{array}$ \\
\hline 6: February 26, 2013 & $\begin{array}{l}\text { Small group discussion: Identifying } \\
\text { personal collusion with oppression }\end{array}$ & $\begin{array}{l}\text { Critical reflection on self- } \\
\text { identification and collusion with }\end{array}$ \\
\hline
\end{tabular}




\begin{tabular}{|l|l|l|}
\hline & $\begin{array}{l}\text { in the food system } \\
\text { Distribution of Personal Action } \\
\text { Lens }\end{array}$ & oppression in the context of food. \\
\hline 7: March 5, 2013 & $\begin{array}{l}\text { Discussion of Personal Action Lens } \\
\text { Brainstorm future visions } \\
\text { Creation of action-oriented nodes }\end{array}$ & $\begin{array}{l}\text { Moving Forward: Co-creating the } \\
\text { series' afterlife }\end{array}$ \\
\hline 8: March 12, 2013 & $\begin{array}{l}\text { Potluck } \\
\text { Group dialogue on future visions: } \\
\text { "Where do we want to go from } \\
\text { here?" } \\
\text { Creation of actionable next steps }\end{array}$ & $\begin{array}{l}\text { Moving Forward: Co-creating the } \\
\text { series' afterlife }\end{array}$ \\
\hline
\end{tabular}




\section{Curriculum}

As elaborated above, the motivation behind the dialogues was to first establish a foundation of understanding and language surrounding oppression, and then use that common understanding to delve into issues of oppression and social justice as they relate to the food system. Following the dialogues on what constitutes oppression, and how oppression operates in the context of food, the final objective of the dialogue series was to encourage participants to co-create visions of future action.

To achieve these goals, we structured the dialogues around exercises and discussion prompts that would guide participants through processes of learning and sharing. Sessions 1 through 4 focused on identifying and naming oppression, and providing participants with a conceptual toolkit for "interrupting" oppression when it occurs. Participants were asked to brainstorm around the question "what is oppression," followed by an exercise in mapping one's social identity. The social identity mapping exercise began with participants listing various forms of oppression in which individuals land on a spectrum of target and agent status. For example, in terms of racism, white individuals generally occupy the agent status, while people of color usually fall closer in line with the target status. After a long list of "-isms" was created, participants were then asked to "map" themselves according to their position on the target-agent spectrum (see Appendix C). The purpose of this activity was to illustrate the multiplicity of oppression present in society, as well as the possibility to simultaneously occupy the target/agent roles, depending on the type of oppression. Building off of the collectively defined understanding of the mechanics of oppression, the focus shifted to how to interrupt in 
moments when oppression is occurring. Participants brainstormed around why or why not interrupt oppression, and practiced identifying and naming how oppression may operate within a series of food-specific scenarios (for a full list of scenarios, see Appendix E).

The food systems scenarios as a component of the anti-oppression training part of the series provided a useful transition to the content in sessions 5 and 6 , in which participants applied this training to their understanding of food systems. In session 5 , participants formed small groups and created concept maps of Portland's food system (see Appendix D). These concept maps illustrated the various nodes of understanding about food in Portland, and provided an interactive method for visualizing urban food issues. The concept maps were then distilled into a list of key food issues (see Appendix F). Participants were then asked to reflect on their individual roles within Portland's food system, and how they might identify with some of the key food issues. Specifically, participants were asked to describe how they might collude with or demonstrate agency in perpetuating oppression (Hardiman \& Jackson, 1997).

After honing in on what oppression is and how it operates in the context of food, in addition to self-reflection on personal accountability and action within systems of oppression, participants then turned to the process of co-creating the dialogue series' afterlife. During sessions 7 and 8, participants reflected on their ideas for personal action, and through small group discussion, produced a list of action-based nodes, including popular education-based strategies such as facilitation of additional dialogues and the development of a food justice resource hub. It was during the final two sessions that the project's emphasis on co-production of visions of future action was most apparent, and 
participants truly drove the process of articulating possible outcomes and self-assorting into action groups.

As outlined in Table 1, the dialogue series was structured around a curricular flow that intended to guide the outcomes of the dialogues themselves. Because the series was also intentionally designed to iterate on observations made during each session, as well as the content of the dialogue as driven by the participants, the curriculum design had to be inherently flexible and adaptable. Infusing the project with this degree of flexibility not only meant that participants were able to engage with the topics they wanted to cover, but also ensured that participant feedback was really at the helm in determining the series' outcomes. Before the dialogues began, the project management group met with the facilitator, Sally Eck, to identify how the series would flow. She was candid from the beginning of curriculum development that we would need to be prepared to abandon ideas for how the series "should" flow in favor of what the participants' needs and interests were. For that reason, the project group met on Thursday of every week of the dialogue series to re-visit what had happened during that week's session, and to plan, based on our observations and feedback received, how to modify the structure of the following week. Indeed, a few sessions were dramatically modified from their original plan. For example, session 4 was originally designed to include an in-depth group analysis of poverty and class in a food-specific context, but because it was evident that the group wanted to spend more time discussion interrupting oppression as discussed in session 3 , the content of session 4 expanded on that work.

Participant Evaluation 
Asking participants to evaluate their experience with the dialogue content and structure was a key ingredient for understanding the impact of the series. In addition to asking participants to evaluate what they had encountered with the dialogues on multiple occasions both during and at the conclusion of the series, participants were solicited on multiple occasions for feedback on how the direction and content of the series might be altered to accommodate the interests of the group. Soliciting written feedback and reflections on the project's content helped ensure that the series was an iterative, flexible experience directly informed by the nature of the conversations taking place.

Following the $4^{\text {th }}$ session, participants were asked to fill out an online mid-point survey that included more detailed questions regarding their experience with the material and format of the dialogues (see Appendix G). Additionally, participants were asked to fill out a brief, handwritten "check-in" evaluation after the $6^{\text {th }}$ and $7^{\text {th }}$ dialogue sessions, answering the following questions: "What is on your mind?" and "Do you have any suggestions for our upcoming work together?" In both the "check-ins" and mid-point evaluation, participants were asked to indicate any additional subjects they wanted covered during the remainder of the series and to provide insight into what topics with resonating or having an impact, as well as any other feedback. Participants also received a final written evaluation, which was completed at the end of the final session of the series. For the final evaluation, participants were asked to reflect on their experience with the dialogue series as a whole, their experience with both the anti-oppression and foodspecific components of the series content, the extent to which relationships and future- 
oriented visions had developed, and their understanding of food and social justice issues before, during, and after completing the series (see Appendix H).

Following session 4, seven participants completed the online midpoint evaluation. At the end of session 6, eight participants completed the brief written feedback form, and 10 participants provided written feedback at the end of session 7. A total of 10 final evaluations were submitted during the final session of the dialogue series, and one final evaluation was submitted via email after the conclusion of the dialogue series. Given the attrition rate for participants, in that we concluded the series with 13 of the original 18 participants but only 9 in attendance for the final session, the evaluation and feedback data collected over the course of the series provides an adequate snapshot necessary to generalize on some preliminary outcomes.

\section{Data Sources and Collection}

This research project provided a rich supply of potential data sources. Multiple data types were collected in each session of the dialogue series. Each session was audio recorded in its entirety. A condition of the project's Human Subjects Research Review Committee approval was the distribution of consent forms to each participant, requesting permission to record and document each session. Signed consent forms were collected in the first session. I also documented each session using descriptive note taking in order to record observations not captured through audio recording, such as participants' body language. My notes also provide a supplemental context to the audio recordings; this additional data source will allow for better analysis of potentially "noisy" audio recordings during future scholarship efforts. We also took digital photographs of all 
written materials, such as the results of brainstorms on the chalkboard and the smallgroup conceptual mapping exercises, were also recorded.

An action research project that brings together a multitude of perspectives such as this one creates a bounty of qualitative data that may be used to address a host of possible research questions. Given that this thesis focuses specifically on the outcomes of the dialogue series through the perspectives of its participants, I restrict my analysis and discussion of emergent themes to the data accumulated in the participants' evaluations and check-ins. In Chapter 5, I will discuss some potential opportunities for subsequent scholarship that have emerged from this dialogue series. With over 10 hours of audio recordings awaiting transcription, paired with notes, observations, and evaluative material, the expectation is that many possible nodes for future scholarship will appear.

\section{Data Coding}

In order to determine what themes emerged from the participants' evaluations and feedback, all of the written and online evaluation text was uploaded into Dedoose, an electronic, cloud-based qualitative analysis program. While other qualitative analysis software was considered, Dedoose was selected for coding the evaluative data because it was most cost-effective and it allowed multiple users to collaborate in the coding process. Collaborative coding is a priority given the multiple potential research lenses that could be applied to the breadth of data collected from the dialogue series, extending beyond the interests of this thesis. ${ }^{8}$

\footnotetext{
${ }^{8}$ While the long-term goals of this project emphasize collaborative, the analysis presented in this thesis is based on my own independent coding. Collaborative coding, particularly of the transcribed session data, is currently taking place.
} 
The intent of my analysis was to observe some of the primary "take-aways" experienced by dialogue participants as expressed through their evaluation of their experiences both during the series and at its conclusion. By articulating some initial observations, they will then inform deeper, more nuanced analysis when applied to the transcribed session data and cross-analyzed with the project management team's observation notes. In order to conduct this analysis, I conducted a simple form of content analysis, a methodological approach through which conceptual insights and meaning are derived from text data through a process of systematic reading, interpretation, and grouping content into thematic categories (Bryman, 2012; Krippendorff, 2012; Elo \& Kyngäs, 2008; Hsieh \& Shannon, 2005). Given the intent of my research, content analysis provided the most appropriate analytical lens by virtue of its methodological flexibility (Bryman, 2012), its utility in examining raw data (Krippendorff, 2012), and its unobtrusive analytical nature that ensure participant reactions were not necessarily colored by an overt perception that they were being "studied" as they responded (Julien, 2008).

To begin my analysis, I conducted an initial open coding process get a sense of the text's general thematic content. My initial readings of the text involved a line-by-line process of characterizing the data while maintaining a focus on participant perceptions of outcomes and impact; how did the participants characterize their experiences? What resonated with them? Following the initial open coding process, I created a list of general thematic categories that helped assemble the responses by their basic subject matter (i.e. "Series logistics," "Reactions"). These general categories codes provided the basis for 
then categorizing the more specific concepts that emerged with more iterative, deeper readings of the evaluations. The data was then read through multiple times for each general category using a coding mechanism consistent with axial coding, in which general categories were fleshed out in order to analyze more nuanced sub-categories (Benaquisto, 2008). For example, following the process of deeper coding, "Reactions" encompassed themes like "confusion," "introduction to new concepts," and "challenged by concepts."

I maintained an inductive approach to coding by developing the general base code list and the more refined sub-code list on the basis of their emergence and repetition in the text, rather than how portions of the text could be limited a priori assumptions about what the participants would reflect on (Tracy, 2012). The evaluative data was derived from responses to open-ended questions about participant experiences (i.e. "what concepts were challenging to you?" and "what's on your mind?"), and the questions were phrased in a manner that ensured that there were many possibilities for how participants would respond. ${ }^{9}$ Because some theoretical constructs foregrounded our more general interest in collecting and examining participant reflections, such as the value in exposure to new or challenging concepts in forging an anti-oppression consciousness, the coding process cannot be defined as purely inductive. But because the language and structure of

\footnotetext{
${ }^{9}$ Illustrating this, questions addressing more specific concepts were left open-ended, versus "yes or no." For example, one of the most direct questions asked regarded the formation of new relationships ("Do you feel that you have been able to develop relationships with any of the other participants (friendship, professional networking, other)?”) In answering, participants were able to provide any kind of answer, and expand on their response. Many reflected not only on how new relationships had formed, but the nature and importance of those relationships.
} 
the evaluations was open-ended enough to permit participants to reflect in new and surprising ways, my analytical approach should not be considered deductive.

While the intent of this thesis is to report on some of the general thematic outcomes of the dialogue series, this analysis does not assume that each participant experienced the series in the same way. The diversity of perspectives represented in the participant group intrinsically suggests a similar diversity of experience. For the midpoint and final evaluations, participants were not asked to rank their reflections by degree of importance, but rather to reflect on different aspects of the dialogue series as a whole. Quantifying the number of instances that a concept or idea appeared across the data does not suggest that the concept carries universal importance for each participant; rather, the concepts that emerged with the greatest frequency are interpreted as particularly emergent for the dialogue series as a whole, and thus warrant further discussion. Exploring both the final impressions of the participants as well as their reflections across the duration of the series also reveals how themes emerged by the end of the series by comparing what was present at the midpoint and at the conclusion. As the analysis presented in the following section suggests, while the experience of the individuals within the group varied as one might expect, some clear and consistent themes emerged.

\section{Reflexivity as Researcher}

The intimate, dialogue-driven nature of this study required that I abandon the traditional "fly-on-the-wall" research stance and actually contribute my voice to the conversation. Engaging with the participatory nature of this study while taking care to observe and document the process is consistent with the values of action research 
(Greenwood \& Levin, 2007), and doing so required me to reflect on whether or not my participation ought to be passive or active. Because the intention behind the dialogue project was to facilitate space for participant reflection, learning, and growth, establishing my participatory role and enhancing my relationship with the other people in the room was key. At the same time, I took care not to affect the direction of conversation too greatly. Because of the highly personal nature of anti-oppression consciousness building, establishing a significant level of trust among dialogue participants was essential for encouraging participants to explore the issues brought up in the dialogues with depth (Adams, 1997). In addition to engaging with the dialogue series in the spirit of research for social transformation, my participation ensured that other participants would be more at ease in the presence of an impartial observer, and would diminish the sense that they were participating in a research project, rather than an a forum for co-creating common understanding and vision.

My ability to establish rapport with participants and build the essential foundation of trust required a reflexive stance on my part. This meant being honest and open when participants had questions about the role of the university and our research agenda at hand, and being candid about my role as note-taker and observer. For example, some participants were either current students or had completed graduate programs in the past, and were curious about the research goals and design. In these conversations, I provided information about the conceptual frameworks driving the development of this project, and discussed the nature and merits of action research methodology. This not only permitted participants a glimpse into what is traditionally obscured information, but may 
have also deepend their situated understanding of their own participation in such a project. Reflexivity is key to interrogating some of the issues of power and access that emerge in the production of social knowledge, specifically in a food justice context (Alkon, 2011). By being reflexive and candid about my role as researcher and the study itself, I was able to enhance the participatory nature of action research.

Reflexivity also contributes to the transformative motivations inherent to this study. Alkon (ibid) argues that reflexive thinking is able to reveal within-group tensions and disparities, and encourages recognition of difference. By examining the situated dynamics of knowledge production, a more thorough understanding of the social world emerges (ibid). To this end, the dialogue participants and I as the researcher relied on reflexive thinking in order to develop and explore the anti-oppression consciousness central to this study. Alkon is quick to point out that reflexivity is not a silver bullet for resolving community-based conflict, but rather an opportunity to interrogate, rather than ignore, differences. This echoes my earlier argument for the politicization for sustainability and sustainable food: while politicization will not immediately resolve social tensions in full, by no longer ignoring difference and dissent, we acquire a deeper understanding of how sustainability might be defined and realized. 


\section{CHAPTER 4: RESULTS \& DISCUSSION}

The participant evaluations provide a valuable window into the perceptions and experiences of those involved in the dialogue series, as well as insights into how future efforts to address conflicts at the intersections of oppression and sustainability might work. Supporting my observations from the evaluations are my own notes from each session, which allowed me to flesh out themes and develop stronger linkages between evaluation comments and what actually happened during the sessions. Overall, the analysis and discussion presented in this thesis is a first take on the host of data collected from the dialogue series, and intends to scaffold future scholarship that draws upon the major themes described here. By no means does the analysis and discussion presented here capture the complexity and depth of the series' outcomes and impact, but rather it establishes a launch point for a deeper understanding of the transformative potential of this work, the successes and limitations of the project design, and the challenges and opportunities that emerge when demands for a heightened consciousness of oppression in the sustainable food discourse are operationalized.

With the evaluation data spanning such a wide conceptual range, it is possible to analyze and unpack how each code appeared in the data (see Appendix I for a full list of codes and references); for example, further analysis of the many references to curriculum recommendations would both provide insight into what may have been missing from the series design, as well as a deeper understanding of what content did and did not resonate for participants. For the sake of brevity, I focus on five emergent themes under the following headings: Collaboration and Relationships, Visions for Future Work, 
Introduction to New and Challenging Concepts, Wanting More, and Diversity and Representation.

\section{Collaboration and Relationships}

Participants were specifically asked to reflect on their experiences with collaboration and new relationships in the final written evaluation, although the above table indicates that some participants reflected on collaboration prior to the conclusion of the series. Participant responses coded as having developed relationships included any reference confirming that the respondent felt connected to at least one other participant. Included with participants who did not form relationships were those who appeared ambivalent about connecting with others, or felt that they did not have adequate time to connect. An expressed interest in future collaboration emerged 10 times across the evaluation data (see Table 2). Seven participants who completed a final evaluation indicated that they felt they had formed new relationships as a result of the dialogue series, and two participants indicated that they had not. Of the participants who said they had formed new relationships, some indicated that they were excited or felt positively about them ("What a wonderful group of people," "[I] hope to stay in touch... personally and professionally," "Yes - and I'm excited about it!").

In addition to reflection on interest in future collaboration, there were two instances of reflection on the conceptual importance of collaboration. In regards to the success of linking issues of oppression to food systems, one participant responded: "What was successful was [having] a designated time to discuss these issues with people who overlapped on these issues, identifying opportunities for partnership and collaboration." 
The same participant also listed "the beginnings... of collaboration" as a primary takeaway from the series.

Table 2: References regarding collaboration and relationships

\begin{tabular}{|c|c|c|c|c|}
\hline & $\begin{array}{c}\text { Mid-point } \\
\text { Evaluation }\end{array}$ & Check-In \#1 & Check-In \#2 & Final Evaluation \\
\hline $\begin{array}{c}\text { Interested in future } \\
\text { collaboration }\end{array}$ & & & 5 & 5 \\
\hline $\begin{array}{c}\text { Relationships } \\
\text { formed }\end{array}$ & & & & 7 \\
\hline $\begin{array}{c}\text { Relationships not } \\
\text { formed }\end{array}$ & & & & 2 \\
\hline $\begin{array}{c}\text { Collaboration is } \\
\text { important }\end{array}$ & & & 2 \\
\hline
\end{tabular}

As I describe in chapter 2, the formation of cross-interest, cross-organizational relationships is key to successful, meaningful organizing around social justice issues. The degree to which relationships formed among participants is central to whether or not future collaboration and action may occur, and contributes to the participants' sense of meaning and belonging in their work. This is especially relevant when considering that several participants did not have a formal professional affiliation, and may require the formation of intentional, informal networks to remain connected to the sustainable food and food justice work occurring in the city.

While forging relationships is fundamental to meaningful community organizing, the impact of developing these networks has the potential to run deep. Throughout the series, participants were not asked to agree about how oppression might look or feel, or to arrive at consensus about what the "right" way to think, feel and act on food justice might be, but rather to embrace the plurality of possibility that critical social justice pedagogy 
teaches (Adams, 1997). The relationships formed during the dialogue series were foregrounded in processes of social learning about the recognition and understanding of difference, oppression, and individual identities, as well as the process of applying this learning in the context of sustainable food and food justice. The plurality of perspectives represented in these processes suggests that the relationships formed among participants share a common ability to relate on these issues, despite the possible differences existing between individuals. Developing relationships among a diverse group of food systems and social justice stakeholders enhances the ability to recognize and appreciate difference. Enhanced recognition of difference is a valuable step towards embracing politically agnostic interpretations of sustainable food, as a heightened understanding of cross-cultural, cross-organizational difference, and the ability to establish common ground in the presence of those differences, may contribute to visions of sustainability and food justice that do not presume the existence of universally appealing solutions, and that make room for the possibility of contingency and dissent.

\section{Visions for Future Work}

The expression of applied and/or future-oriented post-dialogues visioning emerged the most among all of the concepts or themes, with a total of 28 instances (13 instances of applied visioning, 15 of future-oriented visioning; see Table 3). For analysis purposes, "applied visioning" refers to anything indicating that the participant envisions some kind of specific, on-the-ground action, solution, or next step. For example, multiple participants expressing applied visioning suggested replicating the dialogue series in East Portland and other low-income parts of the city in order to capture the participation of 
some marginalized populations. Other participants reflected on the application of the dialogue series content at work ("My current work with elementary school children allows for many opportunities for interruptions than I would've imagined"), while others offered grander visions, yet still focused on the practical application of dialogue content ("I want to continue learning (grad school) about how to create change").

Table 3: References regarding visions for future work

\begin{tabular}{|c|c|c|c|c|}
\hline & $\begin{array}{c}\text { Mid-point } \\
\text { Evaluation }\end{array}$ & Check-In \#1 & Check-In \#2 & Final Evaluation \\
\hline $\begin{array}{c}\text { Applied, on-the- } \\
\text { ground visioning }\end{array}$ & 2 & 2 & 2 & 7 \\
\hline Expand the reach & 1 & & 1 & 12 \\
\hline $\begin{array}{c}\text { Future-oriented } \\
\text { visioning }\end{array}$ & & & 1 & 8 \\
\hline $\begin{array}{c}\text { Motivation } \\
\text { towards action }\end{array}$ & 2 & & & 7 \\
\hline $\begin{array}{c}\text { Professional } \\
\text { Relevancy }\end{array}$ & 2 & & 3 & \\
\hline
\end{tabular}

The demonstration of future-oriented visioning is less specific than applied visioning. Future-oriented visions encompass any reflection indicating that the participant had a sense of momentum and forward-thought surrounding the dialogue content. For this reason, every instance of applied-visioning was also coded as future-oriented, with the exception of those instances in which the participant referred to current work rather than an idea for the future. For this reason, the application of future-oriented visioning is quite diverse across participants. Some participants offered more general visions for their future engagement with the dialogue content ("Looking forward to seeing the momentum continue," "This is a good start," "I would like to know more about the continuing work 
in this area"), while others were more specific ("Quarterly potlucks to update each other on progress and work," "I've been thinking of creating an online node for these issues,"). Future-oriented visioning is essential for the dialogue series' afterlife. The demonstrated ability to conceptualize future action coordinated with the dialogue series content in mind suggests that the participants were interested in applying and testing the concepts they interacted with outside of the workshop model. Future-oriented visioning in tandem with a vested interest in collaboration may indeed be the recipe for action that takes into account the anti-oppression frameworks covered in the dialogue series. As the participants' current rumblings of organizing around the development of a food justice resource and education hub illustrates, the future-oriented visioning demonstrated by participants may result in an expansion and reiteration of the dialogue series' content. For this reason, participants' tendency towards future-oriented visioning may play an important role in mobilizing transformative outcomes that this action research project sought, and highlights one way that it may be considered an effective model.

While there are many promising aspects to this demonstration of future-oriented visioning, possible tensions exist as well. The most consistent form of this kind of thinking about future action was applied visioning, and therefore focused on mobilizing specific solutions and strategies (i.e. brainstorming around questions of "what do we do about this?"). Applied visioning was evident in the mid-point evaluation, and only strengthened by the time the final evaluation was delivered. The emphasis on applied solutions is certainly compatible with the curricular content during the final dialogue sessions, which involved processes of brainstorming around next steps and possible 
futures. But because this kind of applied, solutions-based thinking emerged long before the brainstorming process it introduces the opportunity to reflect on how applied visioning highlights a tendency to reorient towards solutions, outcomes, and possible actions. In dialogue, participants re-directed conversation towards questions of "what do we do next?" and "how do we go about resolving this?" early in the series, and there was a strong emphasis on solutions, strategies, and fixes in the interruptions curriculum in particular. In the final evaluation, one participant resisted the anti-oppression foundations component of the series as a whole, and described the series as resonant only "when we got to the real," with "the real" presumably meaning more applied discussions of possible work, which often involved topics of policy and programming.

There is considerable relevancy in envisioning solutions and strategies that more effectively integrate an anti-oppression consciousness, yet the tension that emerges is that the fixation on applied outcomes may lead to visioning that remains too firmly focused on developing "silver bullet" programs, policies, and tactics that may mobilize antioppression language, but still lack preparedness to acknowledge and embrace possibilities of political contingency and dissent. What happens when well-meaning proposals are met with resistance in the community? This resistance is central to the problems experienced within the sustainability and food justice discourses described in Chapter 2, in which an emphasis on solutions may dismiss or overlook the contested realities in the communities they seek to affect. As the previous section on relationships suggests, many participants may have developed an enhanced ability to recognize and acknowledge difference at the interpersonal level, but the level of preparedness for 
recognizing difference at an organizational or operational level remains less defined. In the following section, I will discuss the specific ideas for possible future work that emerged out of sessions 7 and 8 , and what these ideas might suggest in terms of better defining the group's ability to hone in on operationalizing an anti-oppression consciousness.

\section{Introduction to New and Challenging Concepts}

Overall, there were 13 instances in which participants specifically reflected on their exposure to new concepts during the dialogue series (see Table 4). This outcome speaks to the efficacy of the dialogue series in challenging participants to think about the manifestation of oppression in a food-specific context. Introducing participants to new concepts is essential for interrogating assumptions about food systems work and expanding beyond the holding pattern of conceptualizing sustainable food as a normative condition, enacted by a stable series of technological or spatial solutions. During dialogue around interrupting in food-specific scenarios, participants were asked to consider how some seemingly universal sentiments (i.e. "what this food desert really needs is a farmers' market") might communicate and perpetuate imbalances of power and create spaces of misrecognition. Participants were asked to engage with the complex task of seeing these seemingly positive constructions in a politicized light, and there was a palpable sense of cognitive dissonance when participants were asked to think about food and social justice from these potentially uncomfortable or unfamiliar positions.

Illustrating the impact of this task, some of the examples cited by participants who 
reflected on their experience with challenging new concepts came up during that experience. One participant reflected on the bias implicit in the statement "if people only had the knowledge of what good food is, they would be healthier and more fit," acknowledging that this was a recognition of oppression that emerged as a result of the dialogue series. Another participant reflected on their introduction to the concept of "healthism" and how it affects beliefs and policy surrounding obesity and chronic disease.

Table 4: References regarding new and challenging concepts

\begin{tabular}{|c|c|c|c|c|}
\hline & $\begin{array}{c}\text { Mid-point } \\
\text { Evaluation }\end{array}$ & Check-In \#1 & Check-In \#2 & Final Evaluation \\
\hline $\begin{array}{c}\text { Challenged by } \\
\text { concepts }\end{array}$ & & 1 & 1 & 3 \\
\hline $\begin{array}{c}\text { Introduced to new } \\
\text { concepts }\end{array}$ & 1 & & & 12 \\
\hline Sense of confusion & 1 & 1 & 1 & 1 \\
\hline
\end{tabular}

Not only did participants indicate that they encountered new concepts external to their experience with the food system, but they also indicated that they had developed new ways to reflect on their own experiences and connect them to systems of oppression through specific dialogue curriculum and activities. The exercise in social identity mapping resonated with several participants: "The mapping helped me see where I connect with the oppressor. Usually, I only see myself as part of the oppressed group;" "I realize how my personal experience of feeling excluded (even though I fit the classic demographic) is a universal experience. There needs to be more work done on this;" "Being able to identify systemic oppressions and practice calling them out. And also mapping where I exist on the map/spectrum of oppressed/oppressor". To another 
participant, their exposure to the stages of anti-classist consciousness introduced mid-way through the series was especially useful, reflecting on how they "now see the clear connections to power, privilege, and poverty" as a result of this piece of the curriculum.

Related to exposure to new concepts are the five instances indicating that participants were challenged by the dialogue series content. Broadly, one participant felt challenged by the multi-scale nature of the dialogues, in which participants were asked to reflect across micro-, meso-, and macro-scales: "I'm feeling the whiplash of zooming in and out between micro and macro level action. I would like to stabilize into one mode of action and focus." Another participant referred to the process of self-identifying with how collusion with oppression operates at the individual level as a "mind-bender." Another challenging concept was "reconciling the macro-structural with the micro (personal) accountability," which, when supported by additional analysis of the transcribed session data, will likely prove to be a powerful cognitive obstacle for many participants. These challenges of scale and applicability echo the above section on applied and futureoriented visioning, and some of the tensions that emerge when the emphasis is on locating and settling into solutions-based trajectories without readily embracing the possibility of multiple and potentially competing modes of action.

One participant noted that "nothing [was] unclear, but certainly challenging," and that "materials were presented in an open and affirming way [that] made it accessible." When paired with the above sentiments on locating and acting on solutions, this participant's remarks speak to the messy, difficult nature of "repoliticizing" the sustainable food movement. When sustainable, just food is framed not as a series of quick 
fixes, such as the insertion of grocery stores, community gardens, and farmers markets, but rather an interrogation of oppression, power, and privilege, the motivation to act may be clear, affirming, and accessible, but the means for actualizing sustainable food is not. Agonism is not defined as a series of tangible techniques and solutions, but as a lens through which we can see social and political relations that understand and confront the presence of conflict and difference rather than dismissing it (Mouffe, 1999). It is through this agonist lens that social change may meaningfully occur, given its emphasis on confronting difference and making room for radical possibilities. For this reason, the recognition of difference and power inherent to the anti-oppression consciousness embedded in the dialogue series provides a useful mechanism for effectively interpreting social problems and defining solutions. In hindsight, the dialogue series could have been more effective in assisting participants in resolving the tension between motivation and means for action by more explicitly framing anti-oppression consciousness as a strategy in and of itself, one that could be applied across a diversity of problems and contexts.

The tensions related to exposure to new and challenging concepts described here introduce future opportunities to engage with concepts of power, privilege, and difference with more depth, while highlighting some of the challenges that unfold when attempting to integrate these concepts into the sustainable food movement. But it is also important to acknowledge how the exposure to new and challenging ideas plays a role in the transformative desires of the dialogue series itself. Because a number of participants indicated that they had been exposed to new concepts and ideas that specifically sought out these processes of interrogation, the dialogue series set in motion the kind of iterative 
learning necessary for slowly preparing the food movement to navigate and address disparities and injustices.

\section{Wanting More}

One of the recurrent pieces of feedback we received from participants was that they wanted more time. There were 13 instances of participants reflecting on the lack of time, and participants suggested longer sessions and/or more than 8 sessions (see Table 5). Indeed, discussion each week remained rich throughout each session's 2-hour time frame, and many participants lingered well past the 11 a.m. finish time. One participant suggested that we "expand dialogues to 2.5 hours. Always felt rushed at the end," and another remarked, "I would request trainings be about 2.5 hours at least. They always felt just a little bit short." Feelings of rushing through the material were especially prominent during the food-specific sessions: "I think we could have had at least another week discussing specific topics in food;" "Towards the end sessions could have been longer;" "I think more time was needed for our group to understand our positionality in the food system." Other reflections regarding time revolved around a sense that the work being done in the dialogue series was meaningful in some way, and that participants wanted to continue to engage with it: "I always leave the group inspired to learn and talk more and develop stronger language around these issues, wishing there was more time;" "I think we could have spent more time on looking inward at our place in the systems and how our positions interact with the larger picture." 
Table 5: References regarding wanting more time, education, depth

\begin{tabular}{|c|c|c|c|c|}
\hline & $\begin{array}{c}\text { Mid-point } \\
\text { Evaluation }\end{array}$ & Check-In \#1 & Check-In \#2 & Final Evaluation \\
\hline More time wanted & 1 & & 1 & 12 \\
\hline $\begin{array}{c}\text { More education } \\
\text { wanted }\end{array}$ & 3 & 3 & & 5 \\
\hline $\begin{array}{c}\text { Desire to "go } \\
\text { deeper" }\end{array}$ & 5 & 3 & & 1 \\
\hline
\end{tabular}

The participants' feelings of being rushed or running out of time are outcomes of what I believe was one of the dialogue series' limitations: attempting to fit a rich array of content into too little time. One of the biggest challenges of the series' execution was finding a balance between creating the time and space for casual conversation and reflection central to building relationships, and creating the time and space for deep, meaningful, reflexive, and thorough group dialogue on the series' content. Breaks would often run long and conversations would become tangential, which compromised the amount of time spent on the "meat" of the dialogue series. The consequence of this was that some activities had to be cut short or omitted, such as a facilitated exercise in which participants revealed their social identity maps to the whole group. Yet with this in mind, when reflecting on the lack of adequate time no participant suggested that we spent too much time getting to know one another, and the amount of time spent engaging in casual, relational conversation may have directly contributed to the relationships that formed among participants. This illustrates the valuable nature of these informal relational spaces when engaging in this type of work. For this reason, expanding future dialogue series into 3- or 4-hour sessions would provide the time needed to strike a more effective balance between casual and structured dialogue. 
As the above table describes, the desire to "dig deeper" into the series content was particularly prevalent in the mid-point evaluation, which was delivered between sessions 4 and 5. The feedback given in this mid-point evaluation, coupled with observations made during the first four sessions, is what led us to alter the curriculum in a way that centralized the issues of self-identification with systems of oppression. This illustrates the very flexible, iterative nature of action research projects like the dialogue series, in which we as researchers were able to dynamically course-correct, rather than remaining on a rigidly defined research trajectory. The questions regarding collusion posed to the group

during session 6 were in direct response to the multiple requests that we "go deeper," and as I discuss below, the participants' reactions to questions of collusion suggest that the desire to dig deeper is not without tremendous complexity.

Given that many participants wanted more time to engage with the dialogue content, it comes as no surprise that one of the potential next steps that emerged in sessions 7 and 8 was the formation of a resource hub to continue and expand the processes of learning and sharing. The desire for more, be it time, education, or depth, suggests that participants believed in the value of their experience. The request to spend more time in this intellectual space suggests that the importance and relevancy of the content resonated with participants, in a way that may contribute to their confidence and preparedness in recognizing and dismantling oppression.

\section{“Who isn't at this table?" Diversity and Representation}

A final theme that reappeared with some frequency in the evaluations and checkins is a palpable sense of concern for who wasn't represented in the room, and concern 
about the degree of diversity represented among the participant group. Concern for unrepresented groups is defined as any indication that the participant was reflecting on those voices, perspectives, and interests that may no have been represented at the dialogue series. The desire for more diversity is defined as whenever the participant commented on their perceptions of who was or was not represented in the dialogue series, and explicitly indicated that there was not enough diversity (a vague term, as I later discuss) in the group. There were a total of 9 instances of concern about diversity and 12 instances of concern about unrepresented groups (see Table 6).

Table 6: References regarding concern over diversity and representation

\begin{tabular}{|c|c|c|c|c|}
\hline & $\begin{array}{c}\text { Mid-point } \\
\text { Evaluation }\end{array}$ & Check-In \#1 & Check-In \#2 & Final Evaluation \\
\hline $\begin{array}{c}\text { Concern for } \\
\text { unrepresented } \\
\text { communities }\end{array}$ & 1 & 2 & 1 & 8 \\
\hline $\begin{array}{c}\text { More diversity } \\
\text { needed }\end{array}$ & & & 1 & 8 \\
\hline
\end{tabular}

Questioning the level of diversity in the room and demonstrating concern for unrepresented groups manifested as wanting to hear the voices of other populations directly affected by food injustice, such as farm workers ("More voices. Would have loved to see an actual food grower in here, whether it be a farm worker or small business owner, just for that additional perspective. More diversity"), as well as reflections on how the project's logistics may have affected participation ('Downtown may have been limiting for some people," "Evening could be better to include more people.")

Reflections on the perceived lack of diversity in the room appeared throughout the evaluation data, and several participants observed the dynamics of the group, and made 
the claim that some important degree of diversity was missing: "The group was predominantly white and female. From that lens, it was very representative of those that work in this field but perhaps not so much of those impacted by systemic food oppression;" "This group could benefit from more socio-economic, racial, political diversity;" "Still thinking about who is not at the table, what perspectives are not here and the assumptions we are making, even with the best intentions."

Many participants also conceptualized a heightened degree of diversity in terms of the necessary ingredients for moving the food justice movement forward: "Being intentional to invite overlooked and underrepresented communities impacted by these issues;" "Please reach out to communities of color;" "We didn't talk a lot about who is at the table. How could this be more inclusive and accessible. In the room and in [the food justice] movement," "Issues surrounding diversity and multicultural perspectives. Who is not here in this room with us, and how can we bring them here?;" "I feel that we still have not addressed how we will welcome more diverse voices to the table." Expanding on the reflections captured by the evaluations, a sense of concern about the level of diversity among participants manifested as early as the first session (22 January 2013 Session Notes).

These questions of representation in the dialogue series provide a useful opportunity to reflect on some of the major limitations to the series' design and implementation. To begin, the downtown, university setting of the dialogue series posed a number of challenges for its participants, as well as those who may have considered applying but felt deterred by the location. Downtown Portland is expensive to travel in 
and out of by car, as traffic can be cumbersome and parking at and around PSU is both pricey and limited. Public transportation is certainly a viable option for visiting the campus, but may have proven too challenging for those with children, those who live very far from the university, or those with mobility issues. More critically, the university setting may also be intimidating to those who are not comfortable or adept in systems of higher education in the U.S., in which universities could be interpreted as elitist, exclusive, or unwelcoming spaces.

Similarly, scheduling the dialogues for a weekday morning may have also been prohibitive to those with children (e.g. issues with access to daycare affecting participation), or those with employment that would not permit taking the time away from the workplace to attend. This is especially relevant in considering the nature of wage labor, in which many workers do not receive personal time off and may have inflexible or unpredictable work schedules. This presents a powerful contradiction to consider when reflecting on the nature of the dialogue series itself: If one of the primary concerns of the food justice movement is the exploitation of workers in the food system, many of whom are in constricting wage labor positions as described above, the timing of the series itself may have prohibited the participation of this very group. Indeed, we encountered this precise contradiction during the application phase, as a representative of Adelante Mujeres, an organization that works with farmworkers in Washington County, approached the project management team with concerns about the timing of the sessions, as it conflicted with the harvest schedule for some of the farmworkers in the organization. As a result, one of the Adelante Mujeres program staff was able to attend, but the 
farmworkers they represent were not. ${ }^{10}$ Future dialogues could be held on weekends or in the evening in order to potentially attract those with less forgiving schedules.

Another factor that may have limited who applied to participate in the dialogue series was the snowball-style recruitment method. While the application dissemination crossed a number of institutional, organizational, and topical boundaries, from Portlandbased public health listservs to the international COMFOOD listserv, we are not able to know with any certainty whether or not the application reached all of the populations we wished to hear from. The iterative nature of snowball sampling is on one hand useful for locating hidden populations and reaching a variety of groups when the desired sample (or, in this case, potential applicant) pool is unknown, but snowball sampling also bears the limitation of being a networked, possibly insular recruitment method (Morgan, 2008).

Also potentially limiting the nature of the application process, thereby limiting participation, was the project's web-based communication. The email dissemination and online location of the application are deeply tangled with disparities of computer access and literacy, as those without regular computer access and the familiarity needed to complete the application may have been barred from participation from the very start. Similar to the farmworker example described above, the project management group encountered the problem of web-based communications when we discovered that a community stakeholder with sporadic computer access was unable to complete the application by the deadlines we set. One way to address this problem in future dialogues would be to dedicate additional time to the recruitment process, publicize the application

\footnotetext{
${ }^{10}$ Also complicating the attendance of Adelante Mujeres farmworkers was the lack of available translation services, as many farmworkers in Washington County and elsewhere are Spanish speakers.
} 
in person at community meetings and in community spaces such as churches and retail space, and to provide a paper version of the application.

Another factor that may have limited who applied to the dialogue series is the belated nature of the stipend provided to participants. The stipend was an important way to thank participants for their time and contribution, and to recognize that their time spent in dialogue should be considered valuable work. If a reference had been made in the application to participants receiving compensation for their time in the form of a $\$ 200$ stipend, it is likely that we would have received more applications, especially from lowincome applicants, or those who are under- or unemployed. While the circumstances surrounding the belated stipends were largely due to the complexities involved in institutional budgeting processes, this omission may have had a truly profound effect on who was able to participate.

A final limitation of the dialogue series that affected who was in the room was the requirement of attendance commitment, which was also intimately connected to the stipend, as participants only received the stipend after participating in at least 7 out of the 8 sessions. This commitment may have been too daunting for the schedules of many would-be applications, and it also contributed to the participant group's attrition rate, as unexpected schedule changes and unanticipated workloads led a few participants to abandon the dialogue series. Additionally, the attendance commitment introduced some challenges involving more nuanced, culturally specific conceptualizations of time, attendance, and participation. One participant expressed disinterest in the attendance commitment very early in the series, and appeared to want to drop in and out of the series 
as often as they saw needed. When this participant missed sessions 2 and 3, the project management group asked this participant not to return for the remaining sessions. This participant was upset by this request, and expressed concern over how the values embedded in the seemingly rigid attendance commitment reflected academic, intellectual, and cultural privilege. This participant's concerns presented a valuable opportunity to reflect on how the project management team's understanding of time and commitment are indeed situated and cultural, and that different understandings may exist and significantly affect who comes to the table and when.

With these limitations in mind, the concern over the level of diversity observed introduces some complex issues surrounding the meaning of engaging in anti-oppression consciousness work, and how this level of concern affects the nature of dialogue itself. At first glance, the participants' observations were accurate; the people at the table (both proverbially and literally) appeared to represent the same identity groups, as many were white, and many were women. As one of the specific participant reflection above describes, there is a seemingly disproportionate number of white women working in the fields of sustainable food and food justice (Allen \& Sachs, 2007; Allen, 2013, June), which begs an deeper understanding of the extent to which the dialogue series challenged or reproduced this condition. ${ }^{11}$

However, the project management team occupied the privileged position of having read every participant's application, in which several reflected on their

\footnotetext{
${ }^{11}$ Locating insights regarding the extent to which the mechanics and narratives of the dialogue series challenged the "white women's movement" identity of the food movement falls outside of the scope of this thesis, and would require considerable additional data to satisfy such a socially and temporally complex question.
} 
experiences with poverty, hunger, and cultural difference, illustrating that while mostly invisible to the eye, there was a significant degree of class and cultural diversity present in the room. Given that the social identity mapping exercise was unfortunately not completed in full due to a lack of time, the opportunity for participants to explicitly share their personal histories and identities in a way that might have allowed the group to recognize its internal diversity was thus limited. It is unknown how these concerns over the level of diversity may have changed had the whole participant group been privy to some of the less visible ways that the participants differed, often dramatically, from one another.

With this in mind, some potent questions emerge. How might the project management group know when the "right" degree of diversity is achieved? Is there a "right" level of diversity to have when engaging with topics of oppression? Once a certain quota of people of color are then assembled in the room, there is a considerable risk towards reproducing stereotypes and bias based on the assumption that the various social identity groups represented share the same politics, values, and beliefs. This idea of universal representation is in direct contradiction to the recognition of difference and contingency inherent to political agonism, and threatens to perpetuate the kind of normative thinking that dominates sustainability and food systems discourses. For this reason, while the emergence of this theme suggests that participants were conscious of systems of oppression and hinted at a willingness to recognize some external dynamics of power and privilege, many of the participant reactions of this nature appeared uncritical 
in those demands for more diversity, and seemed to overlook the transformative potential of the specific group that was at the table.

The challenges involved in the kind of critical, reflexive thinking inherent to an anti-oppression consciousness can be seen both in the participant evaluations as described above, as well as in observations on participant interactions with dialogue content. Illustrating this are the reactions observed to questions of positionality and selfidentification with systems of oppression. As previously mentioned, session 6 was dedicated to asking participants to reflect on how they were complicit with systems of oppression in the food system, and what they might lose or give up if they refused to participate in these systems. These questions echoed a prevalent theme in the antioppression training component of the series, which was that systems of oppression are complex, nuanced, and insidious, and that everyone colludes with them in various large and small, conscious and unconscious ways. When participants were asked to discuss how they colluded with systems of oppression specific to food, there was a considerable degree of resistance among many participants to acknowledge how they may be complicit. This was surprising, given the prior work that had been done with the foodspecific interruptions scenarios, in which participants were asked to directly challenge some deeply held assumptions about what strategies were appropriate for a sustainable, just food systems. Some participants resisted session 6's questions of collusion and selfidentification by redirecting the conversation to external debates and critiques, such as farmworkers' rights and environmental degradation, without explicitly situating themselves within those debates. Other participants resisted by redirecting the 
conversation to those previously discussed questions regarding diversity and who wasn't represented at the dialogue table, implying that by raising these questions, they were tacitly admitting their privileged position of participation. Yet other participants resisted by making claims to their expert knowledge in food justice issues, given their experience with various campaigns and community action programs. As these different examples of resistance highlight, the vulnerability induced by these questions of collusion led to a variety of reactions in the participants; for some, the concept of collusion resonated and they were able to reflect on their positionality, and also expressed feelings of discomfort, hopelessness, or confusion. 


\section{CHAPTER 5: IMPLICATIONS \& FUTURE DIRECTIONS}

With these initial observations on events and outcomes of the dialogue series in

mind, some important linkages to the theoretical frameworks described have emerged. These implications provide direction for next steps in terms of future scholarship and additional analysis that would expand upon this thesis' discussion of the dialogue series.

\section{Critical Sustainability}

The concept of agonism was introduced in chapter 2 as a relational approach crucial for "repoliticizing" the sustainability discourse, which contains concepts of food system sustainability. The outcomes of the mainstream, depoliticized visions of sustainable food are often observed as normative, universal prescriptions for how to solve problems. These normative ideals are problematic given that social equity is typically contained within the broader sustainability fabric, as equity and justice are far too messy, complex, and contingent for generalized strategies and often defy "silver bullet" solutions. Inserting a grocery store or farmers market into a space that has been defined as a food desert embodies an approach to equity that considers only the injustices of distribution that might be at play, and without a critical, reflexive basis, may unfortunately miss some of the more nuanced, situated forms of injustice that may perpetuate food insecurity. Sustainability, and in particular food systems sustainability, must mobilize an agonist approach that is prepared to recognize a plurality of justice, and engage with the conflicts implicit in the pursuit of social justice. Through an opening up of the space and processes needed for a more agonist approach to sustainable food and 
food justice, the dialogue series and the outcomes described in this thesis highlight some of the challenges and opportunities that emerge in doing so.

Once room for dissent, difference, and interrogation is made, this space often produces feelings of confusion, conflict, and discomfort. This was readily observed in the participant reactions while reflecting on their complicit role with systems of oppression. The discomfort participants experience in being truly reflexive about their collusion demonstrates just how challenging it is to operationalize the charge towards political agonism that has been described in the critical sustainability and food justice literatures. The resistance demonstrated by participants suggests that in a consensus-driven, conflictaverse apolitical climate for working in sustainable food and social justice, there may be seldom opportunities to critique these motivations, let alone engage in self-critique that calls into question how this movement's practitioners may comply with the very systems of oppression they may be working to change. Following an agonist framework, the community stakeholders involved in the dialogue series are required to regularly mobilize this kind of critical, reflexive thinking in order to produce more effective social equity solutions, and the difficulty encountered in doing so highlights how this resistance may occur on the ground, and the ways in which that resistance might be reproduced in an organizational or community context (i.e. calling into question issues of demographic representation or exerting one's expertise, rather than confronting more difficult questions about systems of oppression and how they are replicated).

But accompanying this formidable challenge in operationalizing a more critical, agonist approach to considering food systems and sustainability are some opportunities. 
The visions for future work captured during sessions 7 and 8 highlight these opportunities. By making space for the recognition of difference and contingency, even with all of the challenges involved in doing so, some of the dialogue series outcomes indicate that the dialogue participants see the value in this space, and are ready to begin to apply it in a broader context. The participant visions for future action included popular education projects like the development of a resource hub or "tool kit" that could be shared with communities as a means for learning and sharing about issues of food justice in Portland; a project that, if materialized, would iterate on the content of the dialogue series. Other visions for future action included simply holding another dialogue series, or developing more food-specific anti-oppression trainings for workplaces or academic environments. What these projects illustrate are visions for future work that strive to enhance and expand consciousness around anti-oppression, and that would continue to make room for engaging with issues of oppression, power, privilege, and justice in the context of sustainable food. Because of how projects and visions like these promise to make space for continued dialogue and potential conflict, they are capable of of "changing the framework that determines how things work" (Zizek, 1999, p. 1999, cited in Swyngedouw, 2007).

\section{Race, Class, and Food}

As previously described, the relevancy of food in everyday life makes it an opportune site for exploring some of the political tensions and debates manifest in the broader sustainability discourse, and what these tensions look like in society. In the sustainable food and food justice movements, we observe some of the situated people and 
organizations involved in carrying out apolitical visions of food system sustainability, as well opportunities for more agonist approaches to overhauling the food system. Food is also a space in which the inability to conceptualize problems and solutions outside of normative assumptions has been observed and critiqued. While defining itself in opposition to the injustices produced throughout the food system, as well as the sustainable food movement, the food justice movement has been critiqued for its struggle to truly embody its social justice ethos in practice.

In response to these critiques, participants were challenged to interrogate some of their presumptions and values about what constitutes an effective and equitable approach, specifically through the food-based interruptions scenarios. For example, participants were asked to consider how the common trope of combatting obesity through food systems reform might reproduce sizist or healthiest values. Interrogating these assumptions opened up the aforementioned space for confusion, dissonance, and conflict, and asked participants to engage with alternate, competing ways of conceptualizing their food-based work. What this dialogue series project has done is facilitated the space needed to encourage what Charles Levkoe describes as "transformative food politics" (2011). Transformative food politics encompasses a critical, reflexive view of food that is conscious of and thus less likely to reproduce the systems of exploitation and oppression for which the sustainable food movement is critiqued, through a consideration of contingency and difference that is broadly characteristic of political agonism.

\section{Action Research}


As researchers with an interest in actively responding to the critiques of food and sustainability described in this thesis, the project team and I needed to find a methodological stance that would give us the capacity to seek our desired outcomes as a part of the research process itself. Action research, with its emphasis on reflexivity, engagement, and social change, provided the necessary tools for executing the dialogue series and its simultaneous goals of producing deeper knowledge on the politics of sustainability and food while facilitating the needed politicization of these fields.

The outcomes of this project highlight the valuable nature of action research as a tool for resolving the tension between more abstract theoretical concepts, like postpolitics or agonism, and community members' applied, on-the-ground practices and beliefs. The intimate, intentional nature of the dialogue series research project illustrates some of the unique qualities of action research in creating spaces that don't necessarily emerge organically, or are not capable of capturing the kind of diverse perspectives that were part of the dialogue series. Because of the relational, interactive, and change-seeking nature of the action research approach, we as researchers were given an opportunity to really embed ourselves in the dialogue series, and intimately observe the challenges and fuzziness involved in operationalizing the theoretical concepts underpinning the project. Action research's dual benefits of knowledge production and social change lent to the richness of the dialogue series' outcomes, and demonstrate how projects such as this can create a host of information and insight that in turn deepens our understanding of the social world. 
As a methodological framework, action research proved valuable in the creation of space that acknowledged the possibility of dissent, conflict, and confusion, space that might contribute to more politicized approaches to sustainable food and food justice. By engaging in research of this kind, in which we were able to put into practice the theoretical concepts foregrounding the research, the project management team and I were able to embody what Patricia Allen (2008) describes as the unique role of the researcher in food justice work, which is distinct from the activist or policy-maker, but rather an agent capable of changing "the way that social conditions are perceived or understood" (p. 160). In the case of the dialogue series, action research provided the tools to simultaneously respond to the calls in the literature for more targeted anti-oppression consciousness in the food justice movement, and to fill some of the gaps between concepts of critical sustainability and Portland's food movement.

\section{Possible Future Directions}

As the outcomes and implications of the dialogue series outline, there is more waiting to be revealed about the dialogue series' impact that fell outside of the of the analytical scope of this thesis.

First, this dialogue series provides an opportunity to look at the discourse and narratives surrounding food systems and social justice as they were articulated and refined by series participants. A closer analysis of the language and framing around oppression and justice found in the transcription data will provide insight into how the themes observed in the evaluations emerged while in dialogue, and how issues were framed by participants. Similarly, discourse analysis of the transcribed data also provides 
an opportunity to interpret how the self-identification of the participants affected their role the dialogues. Specifically, discourse analysis of how participants mobilized various sources of symbolic, cultural, and social capital in discussing food systems and social justice will highlight how definitions of oppression and food justice are contextually operationalized. In this regard, the "perception of expertise" code may highlight some interesting interpersonal dynamics among participants that helped shape the form and function of the dialogue series. For example, one participant frequently referenced their extensive background in food policy work in dialogue as the basis for their more advanced understanding of food justice issues, and similarly reflected on having "been there, done that" with the content in their final evaluation. Further analysis of the transcribed data will provide insight into how demonstrations of expertise such as these operated in the process of co-creating an understanding around food justice issues as a group, and the ways in which these demonstrations guided the dialogue trajectory. At first glance, these demonstrations of expertise also appeared in moments of vulnerability, such as when participants were asked to self-identify with systems of oppression. A deeper look at the framing of these claims of expertise may lend to understandings of how political agonism's complexities play out in dialogue.

Additionally, research exploring this tension between the ability to recognize and lambast sources of oppression and refusal to place oneself within (rather than in strict opposition to) the dominant paradigm may be useful for informing future attempts to raise anti-oppression consciousness. Further analysis of these tensions may also provide valuable insight for possibly resolving some of the challenged experienced when 
engaging with the messy politics of social sustainability, by lending to our understanding of why self-identification of positionality is so hard, as well as the impact this resistance has on meaningfully reckoning with systems of oppression.

Expanding on my observations surrounding participants' concerns about diversity and representation, another opportunity for future research may be to look more closely at how those concerns came out during the sessions, and the extent to which they helped or hindered the transformative potential of the dialogues. During one of our weekly planning meetings, facilitator Sally Eck reflected on how the recurrent criticisms regarding diversity might reveal where the participants landed on what she referred to as "the spectrum of critical anti-oppression consciousness." Sally described how different points on the spectrum might reveal an individual's preparedness to embody antioppression values. As previously discussed, a persistent concern for others illustrates the ability to think critically about power, privilege, and access, but it is but one point on the progression towards anti-oppression consciousness, because this concern can prohibit the individual from important processes of self-reflection and self-identification, and effectively put up "blinders" towards the transformative potential of whatever group the individual happens to be a part of at the time. What the dialogue series provides is a valuable case study of how different points on this spectrum look and function, and what their impact may be on those individuals existing at different points. This creates an opportunity to contribute to the collective body of knowledge on critical pedagogy, and enhance anti-oppression pedagogy outside of the dialogue series' food-specific context. 
A final opportunity for future research is to take a longitudinal approach to the dialogue series, and to follow up with participants about their experiences with the series' content after its conclusion. By exploring how concepts from the series continue to resonate or have fallen out of focus, how participants have or have not applied dialogue series concepts in their outside lives, and the extent to which relationships continue to thrive (or dwindle), we may gain a better understanding of what components of the series were most effective, as well as what concepts carry meaning and value to the participants in their outside lives. 


\section{CHAPTER 6: CONCLUSION}

The outcomes presented in this thesis are a step in the direction towards achieving the much larger goal of changing the discourse on sustainable food. It will take more than eight workshop sessions to provoke radical social change. But as the analysis of the evaluation and feedback data implies, the participants' experiences in the dialogue series may be potent catalysts for reflection, action, and ultimately, social transformation. This is already evident in the months following the conclusion of the dialogue series, as many participants are independently organizing around action items, including the development of a food justice resource and education hub. A handful of participants are in the process of coordinating a series of upcoming meetings to discuss opportunities for future collaboration, and other participants have reported back to the project management group on how they have been able to integrate concepts into their professional and community work since the conclusion of the series. Additionally, we have been contacted on multiple occasions since the commencement of the first session to inquire if and when we intend on holding a second dialogue series. While these small actions may not automatically resonate as revolutionary, they do suggest a staying power to the dialogue content and formidable sense of collaborative momentum around meaningful organizing for food justice.

One participant appeared to be particularly affected by her experience with the dialogue series, when she writes, "The series has been life changing for me. I am orienting my future around food justice." While only explicitly evident in the testimonial of one person, this illustrates the potential for meaningful, intentional dialogue in 
supporting reflexive, transformative food politics capable of opening up the ways that we collectively think about sustainability, food, and justice (Levkoe, 2011; DuPuis \& Goodman, 2005). By creating space and encouraging community stakeholders to look at their world in new, challenging, and potentially difficult ways, and to forge relationships that hinge on the recognition of difference, these kinds of justice-oriented, politically contingent, and ultimately more promising visions of sustainability can emerge. 


\section{REFERENCES}

Adams, M. (1997). Pedagogical frameworks for social justice education. In: Adams, M., Bell, L. A., \& Griffin, P. (eds). Teaching for diversity and social justice: A sourcebook. New York, NY: Routledge. 30-44.

Adelante Mujeres. (n.d.) "Programs overview.” Retrieved May 13, 2013 from http://www.adelantemujeres.org/programs-overview/.

Agyeman, J. 2005. Sustainable Communities And The Challenge Of Environmental Justice. New York: NYU Press.

Aigner, S., Raymond, V., \& Smidt, L. (2002). "Whole community organizing" for the 21st Century. Community Development, 33(1), 86-106.

Alkon, A. H. (2011). Reflexivity and environmental justice scholarship: A role for feminist methodologies. Organization \& Environment, 24(2), 130-149.

Alkon, A. H. (2012). Black, white, and green: Farmers markets, race, and the green economy. Athens: University of Georgia Press.

Alkon, A. H., \& Agyeman, J. (2011). Cultivating food justice : race, class, and sustainability. Cambridge, Mass.: MIT Press.

Alkon, A. H., \& Mares, T. M. (2012). Food sovereignty in US food movements: radical visions and neoliberal constraints. Agriculture and Human Values, 29(3), 347-359. doi:10.1007/s10460-012-9356-Z

Alkon, A. H., \& Norgaard, K. M. (2009). Breaking the food chains: An investigation of food justice activism*. Sociological Inquiry, 79(3), 289-305.

Allen, P. (2004). Together at the table: sustainability and sustenance in the American agrifood system. University Park, PA: Pennsylvania State University Press.

Allen, P. (2008). Mining for justice in the food system: perceptions, practices, and possibilities. Agriculture and Human Values, 25(2), 157-161.

Allen, P. (2013, June). Dancing with (not around) the elephants in the room: Building sustainable and equitable food systems for all. Keynote Address. Lecture conducted from the Canadian Association for Food Studies 2013 Assembly, University of Victoria, Victoria, BC.

Allen, P., \& Sachs, C. (2007). Women and food chains: The gendered politics of food. International Journal of Sociology of Food and Agriculture. 15(1), 1-23. 
Allmendinger, P., \& Haughton, G. (2012). Post-political spatial planning in England: a crisis of consensus? Transactions of the Institute of British Geographers, 89-103. Retrieved from http://onlinelibrary.wiley.com/doi/10.1111/j.14755661.2011.00468.x/full

Benaquisto, L. (2008). Content analysis. In: Given, L. M. (ed.) The SAGE encyclopedia of qualitative research methods. Los Angeles, Calif: Sage Publications, 52-53.

Berry, G. R. (2003). Organizing against multinational corporate power in cancer alley: The activist community as primary stakeholder. Organization \& Environment, 16(1), $3-33$.

Block, J. P., Scribner, R. A, \& DeSalvo, K. B. (2004). Fast food, race/ethnicity, and income: a geographic analysis. American journal of preventive medicine, 27(3), $211-7$.

Bonilla-Silva, E. (2003). Racism without racists: Color-blind racism and the persistence of racial inequality in the United States. New York: Rowman B. Littlefield.

Brown, M.K., Carnoy, M., Duster, D.B., \& Oppenheimer, D.B. (2003). Whitewashing race: The myth of a color-blind society. Berkeley: University of California Press.

Bryman, A. (2012). Social research methods. Oxford: Oxford University Press.

Carlisle, L. (2013). Critical agrarianism. Renewable Agriculture and Food Systems, 1-11.

Cheek, J., (2008). Healthism: a new conservatism? Qualitative Health Research, 18(7), 974-982.

Clarke, A. (2005). Situational analysis: Grounded theory after the postmodern turn. Thousand Oaks, Calif: Sage Publications.

Davidson, M. (2009). Social sustainability: a potential for politics? Local Environment, 14(7), 607-619. doi:10.1080/13549830903089291

DeLind, L. (2002). Place, work, and civic agriculture: Common fields for cultivation. Agriculture and Human Values, 19(3), 217-224.

Dillard, J. F., Dujon, V., \& King, M. C. (2009). Understanding the social dimension of sustainability. New York: Routledge.

DuPuis, E. M., \& Goodman, D. (2005). Should we go "home" to eat?: toward a reflexive politics of localism. Journal of Rural Studies, 21(3), 359-371. 
East Portland Action Plan. (n.d.). "Committees and representatives.” Retrieved May 13, 2013 from

http://eastportlandactionplan.org/sites/default/files/2013.04.05\%20Committees $\% 20$ $\& \% 20$ Representatives.pdf.

Eisenhauer, E. (2001). In poor health: Supermarket redlining and urban nutrition.

GeoJournal, 53, 125-133. Retrieved from

http://link.springer.com/article/10.1023/A\%3A1015772503007

Elo, S., \& Kyngäs, H. (2008). The qualitative content analysis process. Journal of Advanced Nursing, 62(1),107-115.

Evans, B. (2006). 'Gluttony or sloth': Critical geographies of bodies and morality in (anti)obesity policy. Area. 38(3), 259-267.

Feenstra, G. (1997). Local food systems and sustainable communities. American Journal of Alternative Agriculture, 12(01), 28-36.

Greenwood, D.J. \& Levin, M. (Eds.). (2007). Introduction to Action Research. (2 ${ }^{\text {nd }}$ ed.). SAGE Publications, Inc. doi: 10.4135/9781412984614

Growing Gardens. (n.d.). “About us.” Retrieved May 13, 2013 from http://growinggardens.org/about-us/.

Gunder, M. 2006. Sustainability: Planning's saving grace or road to perdition? Journal of Planning Education and Research 26 (2):208-221.

Guthman, J. (2003). Fast food/organic food: Reflexive tastes and the making of "yuppie chow". Social \& Cultural Geography, 4(1), 45-58.

Guthman, J. (2008a). "If they only knew": Color blindness and universalism in California alternative food institutions. The Professional Geographer, 60(3), 387-397.

Guthman, J. (2008b). Bringing good food to others: investigating the subjects of alternative food practice. Cultural Geographies, 15(4), 431-447.

Guthman, J. (2011). Weighing in : obesity, food justice, and the limits of capitalism. Berkeley: University of California Press.

Hardiman, R. \& Jackson, B.W. (1997). Conceptual foundations for social justice courses. In: Adams, M., Bell, L. A., \& Griffin, P. (eds). Teaching for diversity and social justice: A sourcebook. New York, NY: Routledge. 16-30. 
Hartley, M. \& Harkavy, I. (2010). Engaged scholarship and the urban university. In: Burack, C. \& Seifer, S. D. \& Fitzgerald, H. \& Votruba, J.(eds.) Handbook of Engaged Scholarship, Vol. 1: Institutional Change. East Lansing, MI: Michigan State University Press.

Hinrichs, C. (2003). The practice and politics of food system localization. Journal of Rural Studies, 19, 33-45.

Hsieh, H. F., \& Shannon, S. E. (2005). Three approaches to qualitative content analysis. Qualitative Health Research, 15(9), 1277-88.

Hustedde, R. J., \& Ganowicz, J. (2002). The basics: What's essential about theory for community development practice? Community Development, 33(1), 1-19.

Johnston, J., \& Szabo, M. (2010). Reflexivity and the Whole Foods market consumer: The lived experience of shopping for change. Agriculture and Human Values, 28(3), 303-319.

Julien, H. (2008). Content analysis. In: Given, L. M. (ed.) The SAGE encyclopedia of qualitative research methods. Los Angeles, Calif: Sage Publications, 121-123.

Kindon, S. L., Pain, R., \& Kesby, M. (2007). Participatory action research approaches and methods: Connecting people, participation and place. London: Routledge.

Kitchen Commons. (n.d.) "About us.” Retrieved May 13, 2013 from http://www.kitchencommons.net/about.

Kloppenburg, J., Hendrickson, J., \& Stevenson, G. W. (1996). Coming in to the foodshed. Agriculture and Human Values, 13(3), 33-42.

Krippendorff, K. (2012). Content analysis: An introduction to its methodology. Thousand Oaks: SAGE.

LeBesco, K. (2011). Neoliberalism, public health, and the moral perils of fatness. Critical Public Health, 21(2), 153-164.

Levkoe, C. Z. (2011). Towards a transformative food politics. Local Environment, 16(7), 687-705.

Lockie, S. (2008). Responsibility and agency within alternative food networks: assembling the "citizen consumer." Agriculture and Human Values, 26(3), 193-201.

Lubitow, A. \& Miller, T. Forthcoming. Contesting sustainability: Bikes, race, and politics in Portlandia. Environmental Justice. 
Magis, K. \& Shinn, C. (2009). Emergent principles of social sustainability. In: Dillard, J. F., Dujon, V., \& King, M. C. (eds.) Understanding the social dimension of sustainability. New York: Routledge.

Marcuse, P. (1998). Sustainability is not enough. Environment and Urbanization 10(2): 103-111.

McClintock, N. (2011). From industrial garden to food desert: Demarcated devaluation in flatlands of Oakland, California. In Alkon, A. H., \& Agyeman, J. (eds.). Cultivating food justice : race, class, and sustainability. Cambridge, Mass.: MIT Press.

McTaggart, R. (1994). Participatory action research: Issues in theory and practice. Educational Action Research, 2(3), 313-337.

Miller, T. R. (2013). Constructing sustainability science: Emerging perspectives and research trajectories. Sustainability Science, 8(2), 279-293.

Moore, J. (2004). Living in the basement of the ivory tower: a graduate student's perspective of participatory action research within academic institutions. Educational Action Research, 12(1), 145-162.

Morgan, D. (2008). Snowball sampling. In: Given, L. M. (ed.) The SAGE encyclopedia of qualitative research methods. Los Angeles, Calif: Sage Publications, 816-817.

Mouffe, C. (1999). Deliberative democracy or agonistic pluralism? Social Research, 66(3), 745-758.

Mouffe, C. (2005). On the political. London: Routledge.

"Multnomah Food Action Plan: Executive summary." (2010). Retrieved from http://multnomahfood.org/sites/multfood.apps.multco.us/files/MFAP exe sum.pdf

Oregon Food Bank. (n.d.). “About us.” Retrieved May 13, 2013 from http://www.oregonfoodbank.org/About-Us.

Reason, P., \& Bradbury, H. (Eds.). (2008). The SAGE Handbook of Action Research. (2nd). SAGE Publications Ltd. doi: 10.4135/9781848607934

Redclift, M. (2005). Sustainable development (1987-2005): An oxymoron comes of age. Sustainable Development, 13(4), 212-227.

Saguy, A., \& Riley, K. (2005). Weighing both sides: Morality, mortality, and framing contests over obesity. Journal of Health Politics, Policy and Law, 30(5), 869-921. 
Sbicca, J. (2012). Growing food justice by planting an anti-oppression foundation: opportunities and obstacles for a budding social movement. Agriculture and Human Values, 29(4), 455-466.

Slocum, R. (2006). Anti-racist practice and the work of community food organizations. Antipode, 38(2): 327-49.

Slocum, R. (2007). Whiteness, space and alternative food practice. Geoforum, 38(3), $520-533$.

Slocum, R. (2010). Race in the study of food. Progress in Human Geography, 35(3), $303-327$.

Stall, S., \& Stoecker, R. (1998). Community organizing or organizing community?: Gender and the crafts of empowerment. Gender \& Society, 12(6), 729-756.

"Summit Summary," (2012). Retrieved November 11, 2012 from http://www.multnomahfood.org/sites/multfood.apps.multco.us/files/Summit Summary.pdf

Swyngedouw, E. (2007). Impossible "sustainability" and the postpolitical condition. In: Krueger, R. \& Gibbs, D. (eds.) The Sustainable Development Paradox: Urban Political Economy in the United States and Europe. New York: The Guildford Press, $13-40$.

Tracy, S. J. (2012). Qualitative research methods: Collecting evidence, crafting analysis, communicating impact. Chichester: Wiley.

Travers, K. D. (1997). Reducing inequities through participatory research and community empowerment. Health Education \& Behavior, 24(3), 344-356.

Urban Gleaners. (n.d.). “About us.” Retrieved May 13, 2013 from http://urbangleaners.org/about-us.

Vallance, S., Perkins, H. C., \& Dixon, J. E. (2011). What is social sustainability? A clarification of concepts. Geoforum, 42(3), 342-348.

Vos, R. O. (2007). Defining sustainability: a conceptual orientation. Journal of Chemical Technology and Biotechnology, 82(4), 334-339.

Walker, G. (2009). Beyond distribution and proximity: Exploring the multiple spatialities of environmental justice. Antipode, 41(4), 614-636. 
World Commission on Environment and Development, (1987). Our Common Future.

Oxford University Press, USA.

\section{APPENDIX A: APPLICATION \\ Community Dialogue on Food \& Justice: Who is at the Table? A Dialogues Series hosted by Portland State University $\&$ the Institute for Sustainable Solutions}

Program Description: This dynamic, participatory workshop series will provide Portland's social justice and food systems activists the opportunity to collaborate, learn, network, and co-produce anti-oppression strategies and best practices. Participants will be asked to engage in reflective thinking to examine their position as advocates for systemic change in our city, in order to help foster the multi-racial, multi-ethnic, cross-class alliances necessary to transform the food movement into a vibrant food justice movement, while giving social justice leaders an opportunity to integrate issues of food to their platforms and programs.

This 8-week series will be structured as a series of 2-hour workshops, giving participants the time and space to "unpack" issues of race, class, and difference in both a social justice and food systems context. Participants will co-create desired outcomes and the project's 'afterlife.' Possible outcomes may include:

- City-wide resource/knowledge network

- Policy advocacy

- Convening event or publication

- Community forum

- Continue with dialogue series

The dialogue series will be led by Sally Eck. Sally Eck is Senior Teaching Faculty in the Women, Gender and Sexuality Studies Department at Portland State University. She teaches courses covering a range of topics from Girls' Studies and Gender \& Education, to Interrupting Oppression. She is also a trainer and workshop facilitator and guest lecturer. All of her work is infused with a commitment to co-creating positive social change through social justice.

\section{Application (to be input into web form):}

Part I: Information. Answers to any of the questions below will neither guarantee nor exclude you from participating. 
1. Name:

2. Age [note - participants must be age 18 or older]:

3. Gender affiliation (if any):

4. Racial identity:

5. Primary language spoken:

6. Will you require translation services, sign language, or any other assistance in order to participate?:

Part II: Availability: To create trust among group members and build on the conversations week to week, we are asking for a commitment to participation. If you are unable to commit to a minimum number of sessions, this may impact your ability to participate.

7. Are you able to commit to at least $7 / 8$ (ideally $8 / 8$ ) workshop sessions?

8 . Please list your most preferred date and time, ranking in order and specifying when it would exclude you:

- Tuesdays: 9am-12pm:

- Choice 1 Choice 2 Choice 3 Can not participate at this time

- Wednesdays: 5pm-8pm:

- Choice 1 Choice 2 Choice 3 Can not participate at this time

- Thursdays: 9-12am:

- Choice 1 Choice 2 Choice 3 Can not participate at this time

9. Please list your organizational affiliation if applicable.

Part III: [please limit answers to approximately 100 words unless stated otherwise]

1. Please describe your understanding of social justice. If you are representing an organization, feel free to include how social justice is defined and applied at an organizational level.

2. Please describe your understanding of food systems work. If you are representing an organization, feel free to include how food systems work is defined and applied at an organizational level.

3. Please list your experience working with diverse viewpoints. 
4. Please list your experience examining issues of oppression, privilege (your breadth or lack of experience will not affect your chances of being accepted into the dialogues - this is to understand group dynamics)

5. Please list your experience examining food systems issues (your breadth or lack of experience will not affect your chances of being accepted into the dialogues - this is to understand group dynamics)

6. How do you plan to share your experience with the broader community and/or the community you are representing?

7. Statement of Purpose: What do you hope to get out of participating in a dynamic, iterative, group-led workshop series that attempts to bridge the gap between social justice and food systems reform in our city? How do you see this project and its potential outcomes impacting the city as a whole? [approx. 100-300 words]

8. Consent [use of dialogue minutes, definitions, etc]: 


\section{APPENDIX B: APPLICANT SELECTION CRITERIA}

Reviewer \#1:

Reviewer \#2:

The overall goal of this application review is to develop a group dynamic based on people who are not normally part of the discussion; who have experience with the content (any of it); who are new to the content; and to those that have strong visions for moving the work beyond the dialogue series. With that in mind, we will use the following criteria to determine a successful and positive group experience shared by the participants.

Reviewer, please complete the following in relation to the applicant:

\section{Part I \& II:}

1. Name:

2. Age:

3. Gender affiliation (if any):

4. Primary language spoken:

5. Other assistance necessary: $\mathrm{Y} \mathrm{N}$

6. Able to commit to at least $7 / 8$ : Y N

\section{Part III:}

7. Organizational affiliation: $\mathrm{Y} \mathrm{N}$

Name:

Social Justice

Food Systems

$P S U$

None

8. Previous experience in food systems work

A lot $(10+$ years $)$

A good amount ( $7+$ years)

Some (5+ years)

A little $(1+$ years $)$

None ( $0-1$ years)

9. Previous experience in social justice work
A lot $(10+$ years $)$ 
A good amount $(7+$ years $)$

Some $(5+$ years $)$

A little $(1+$ years $)$

None (0-1 years)

10. Describe social justice as it is understood and applied:

Great understanding

Moderate understanding

Limited understanding

Other/notes:

11. Describe how food systems work is understood and applied:

Great understanding

Moderate understanding

Limited understanding

Other/notes:

12. Please list your experience working with diverse viewpoints.

Great experience

Moderate experience

Limited experience

Other/notes:

13. Please list your experience examining issues of oppression, privilege:

Great experience

Moderate experience

Limited experience

Other/notes:

14. Please list your experience examining food systems issues:

Great experience

Moderate experience

Limited experience

Other/notes:

15. How do they plan to share their experience with the broader community and/or the community they are representing?

16. Statement of Purpose Summary: 


\section{Evaluation}

Recommendation from reviewer \#1:

Approve:

Consider:

Not a good fit:

Recommendation from reviewer \#2:

Approve:

Consider:

Not a good

fit: 
APPENDIX C: SOCIAL IDENTITY MAPPING BRAINSTORM

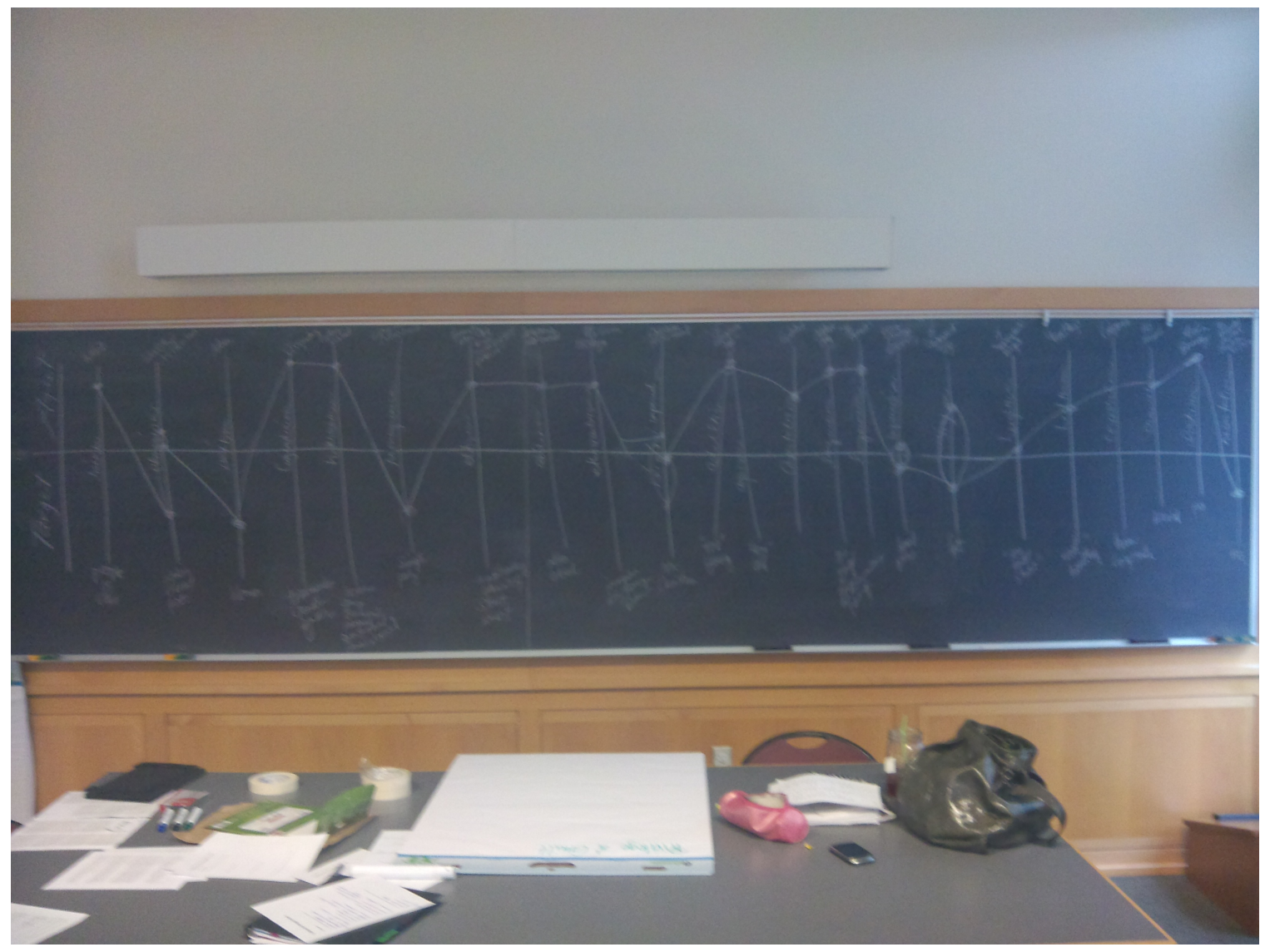


APPENDIX D: EXAMPLE OF CONCEPTUAL MAP OF FOOD IN PORTLAND

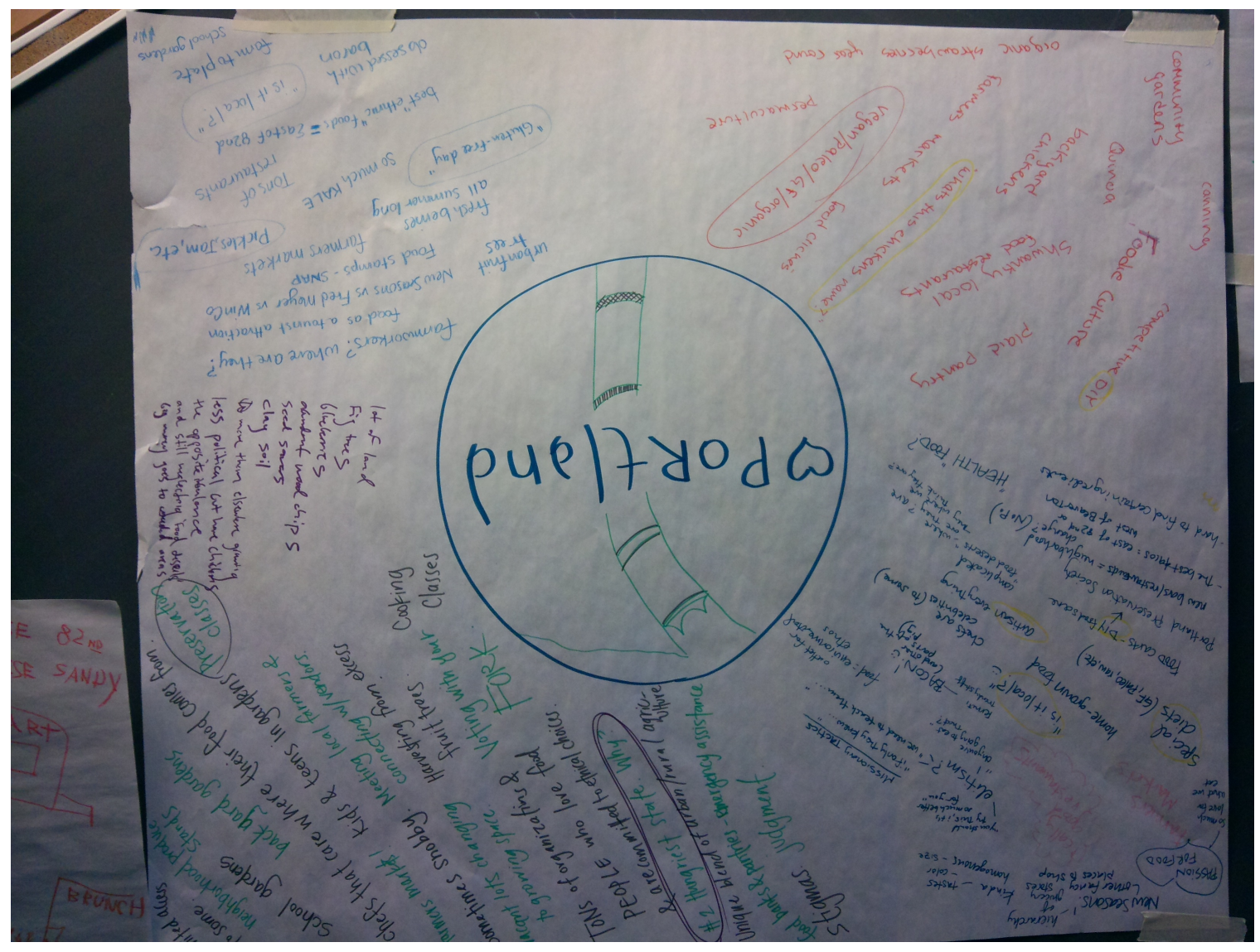




\section{APPENDIX E: INTERRUPTIONS 101 \& SCENARIOS}

\section{Interruptions 101}

Interruptions are a set of skills that we can use to create space for dialogue and rethinking oppression in our communities. This primary goal of interrupting has several objectives. The objectives of an interruption are: to encourage respectful communication, to deconstruct "-isms" (recognize and name stereotypes and their contribution to structural violence), create a respectful space for everyone to participate, to educate, and to learn something together. These skills can be effective in our work and personal lives. The following lists skills to get started. Keep in mind, you probably already do these! Being aware of a variety of ways of doing an interruption can add tools to your cognitive and interpersonal toolbox. On a separate sheet of paper, please, add to this list. (When you think of more, please, share them with me! I would love to add them to this workshop! learnheartwork@gmail.com)

\section{Skills}

Here are some skills to remember, every time you do an interruption:

- Think well of one another.

- Demonstrate patience.

- Know your objective.

- Share new information.

- Demonstrate your leadership skills.

- Be aware of your use of non-verbal communication (demonstrate warmth and understanding, when you can, with your body language).

- Dialogue.

- Follow your instinct. (Does it seem oppressive, but you're not sure? If you have the hunch, it is often worth pursuing.)

- While interrupting may be the right thing to do, it is not, necessarily about being "right."

- Always, ALWAYS, be interruptible...this includes interrupting one's self before anyone needs to interrupt as well as being accepting of interruptions from others.

Here are some other skills that may or may not be appropriate, you may think of them as tools with specific uses (ie. A hammer is more effective with a nail than with a bolt):

- Teamwork-use friends if it would help or policy as back-up.

- Ask clarifying questions.

- Speak from personal experience.

- Use humor when applicable.

- Make or draw parallels.

- Include positive and validating comments.

- Know what you know... access additional resources when you don't.

- Breather, take a break.

- "I statements" can be helpful.

- Give the invitation to dialogue. 
- Be non-judgmental; we are in this together!

\section{Interruption Scenarios}

"That's a ghetto market."

"That's ghetto food."

"If people just grew their own food, then they wouldn't need food stamps."

"If people just grew their own food, then they would not have to eat junk food."

"What this food desert really needs is a farmers market and a community garden!"

"Good food costs more because it's higher quality. It's worth it."

"Fat people are fat because they eat so much junk food!"

"The only way to cure the obesity epidemic is to change the way we eat."

"If we could all just get our hands dirty in the soil, we'd all understand how important it is to have a sustainable food system."

"You should try vegetarian/vegan/Paleo/gluten-free/etc., it'll make you feel so much healthier."

"If everyone ate vegan, we would solve all of these environmental and health problems" 
APPENDIX F: KEY FOOD ISSUES

\section{Key Food Issues in Portland - FJD Group Map}

From Session 5 - Feb 192013

- The "Foodie" Capital of Portland

- Food Trends

- Diets: gluten-free, paleo, organic, vegan, etc.

- Farm to Fork/Know your farmer/buy local/slow food

- Artisan/DIY/culturally-specific foods

- food experiences are "rarified"

- Food tourism \& national reputation

- Food Hierarchies

- "Food movement imperialism"

- passive progressive/missionary-style elitism

- Abundance \& Scarcity: Willamette Valley/Pacific NW Region

- Productive soil, abundant produce, etc.

- Huge farming population with lots of small farmers

- Tensions:

- Those who grow our food experience food insecurity

- $\quad$ OR is the 2 nd hungriest state

- $\quad$ Spatial Inequalities \& Food

- "The 205 divide" as example of unequal access \& income inequalities

- "inner versus outer" mentality

- inner part of city more 20-40s, single/no kids, affluent

more SNAP in outer parts of city; less access

Where is "authentic" ethnic food found in the city?

Isolation of ethnic food

concentration of "healthy" groceries \& restaurants 


\section{APPENDIX G: MIDPOINT ONLINE EVALUATION}

\section{Mid - Point Food Justice Dialogue Series Check In}

Thank you so much for being a part of the first run of the Food Justice Dialogue program. Your feedback is absolutely essential to us, and we'd love to hear from you! Your responses will be anonymous, so please be as candid (or reserved!) as you feel comfortable with.

\section{Please rate your experience so far:}

$$
\text { Awesome Pretty good } \begin{gathered}
\text { It's been } \\
\text { alright }
\end{gathered} \text { Not great } \begin{gathered}
\text { Needs to } \\
\text { improve }
\end{gathered}
$$

\section{Training on topics of oppression}

Access to resources to increase my learning

New ways of thinking about how oppression exists in the food systems

The overall social justice component of the dialogue series (sessions 1-3)

Please feel free to elaborate on any of your above answers.

What concepts have been most useful for you in understanding interruptions?

Are there any examples of oppression in food systems that you have recognized since the dialogue series began? If so, please explain briefly.

What do you hope to learn more about in the last four weeks of our time together?

Have you considered a project or outcome for the group to pursue?

\section{I would recommend this series to a friend or colleague}

Yes

I would consider it

If it came up in conversation, I might mention it

Probably not

Anything else you want us to know? 


\title{
APPENDIX H: FINAL EVALUATION
}

\author{
Food Justice Dialogues: End of Series Evaluation \\ Session \#8: 12 March 2013
}

Name (optional):

Logistics and Organization:

On a scale from 1 to 10 , how would you rate the overall logistics and facilitation of the dialogue series as a whole?

$$
\begin{array}{llllllllll}
1 & 2 & 3 & 4 & 5 & 6 & 7 & 8 & 9 & 10
\end{array}
$$

How was the balance of small group and large group conversations?

What was your experience regarding communication of meeting logistics, directions for activities, facilitator, and coordinator needs?

Did the location of the series help or hinder your participation?

Would you change the frequency ( 8 sessions) and / or time ( 2 hours) of the series? Why or why not?

\section{Topics on Anti-Oppression:}

On a scale from 1 to 10, how would you rate the anti-oppression training component of the series (ex: defining and identifying oppression, interruptions)? $1=$ awful, $10=$ amazing

$$
\begin{array}{llllllllll}
1 & 2 & 3 & 4 & 5 & 6 & 7 & 8 & 9 & 10
\end{array}
$$

Think about the anti-oppression training component of the series (ex: defining oppression, interruptions). Was it effective? How might it be improved?

What concepts have been most useful?

What concepts have been particularly challenging or unclear?

\section{Topics on Food Systems:}

On a scale from 1 to 10 , how would you rate the food-specific dialogue component of the series (ex:

conceptual mapping, individual action lens)? $1=$ awful, $10=$ amazing

$$
\begin{array}{llllllllll}
1 & 2 & 3 & 4 & 5 & 6 & 7 & 8 & 9 & 10
\end{array}
$$


Think about the food-specific dialogue component of the series (ex: conceptual mapping, individual action lens). How did it succeed? How might it be improved?

Were you introduced to new ways of thinking about how food systems and oppression might intersect? Please describe.

Carrying the work forward:

On a scale from 1 to 10 , how likely do you feel that this work is or will become relevant to your personal and/or professional work? $1=$ not likely at all, $10=$ extremely likely

$$
\begin{array}{llllllllll}
1 & 2 & 3 & 4 & 5 & 6 & 7 & 8 & 9 & 10
\end{array}
$$

How might you apply something you've learned or done here in your personal and/or professional work?

Do you feel that you have been able to develop relationships with any of the other participants (friendship, professional networking, other)?

What are your 'take-aways' from this series?

What was missing from this series?

Would you recommend this series to a friend or colleague? Why or why not?

Any other reflections, suggestions, or comments? 


\section{APPENDIX I: APPLICATION OF CODES}

\begin{tabular}{|c|c|c|c|c|c|c|}
\hline Base Code & \multicolumn{2}{|c|}{ Sub-codes } & $\begin{array}{l}\text { Mid-Point } \\
\text { Evaluation }\end{array}$ & $\begin{array}{l}\text { Check- } \\
\text { In \#1 }\end{array}$ & $\begin{array}{l}\text { Check- } \\
\text { In \#2 }\end{array}$ & $\begin{array}{c}\text { Final } \\
\text { Evaluation }\end{array}$ \\
\hline \multirow[t]{4}{*}{$\begin{array}{l}\text { Collaboration and } \\
\text { Networking }\end{array}$} & \multicolumn{2}{|c|}{$\begin{array}{l}\text { Interested in future } \\
\text { collaboration }\end{array}$} & & & 5 & 5 \\
\hline & \multicolumn{2}{|c|}{ Relationships formed } & & & & 7 \\
\hline & \multirow{2}{*}{\multicolumn{2}{|c|}{ Relationships not formed }} & & & & 7 \\
\hline & & & & & & $\frac{2}{2}$ \\
\hline \multirow[t]{9}{*}{ Dialogue Content } & \multirow[t]{2}{*}{ Interruptions } & $\begin{array}{l}\text { Interruptions } \\
\text { were not } \\
\text { useful }\end{array}$ & 3 & & & $\frac{2}{1}$ \\
\hline & & $\begin{array}{l}\text { Interruptions } \\
\text { were useful }\end{array}$ & & & & 1 \\
\hline & \multicolumn{2}{|l|}{ Too academic } & & & & 2 \\
\hline & \multicolumn{2}{|l|}{ Too theoretical } & & & & 2 \\
\hline & \multicolumn{2}{|l|}{$\begin{array}{l}\text { Anti-oppression } \\
\text { training good }\end{array}$} & 3 & & & 1 \\
\hline & \multicolumn{2}{|l|}{$\begin{array}{l}\text { Anti-oppression } \\
\text { training not } \\
\text { good }\end{array}$} & & & & 1 \\
\hline & \multicolumn{2}{|l|}{$\begin{array}{l}\text { Desire to go } \\
\text { deeper }\end{array}$} & 5 & 3 & & 1 \\
\hline & \multicolumn{2}{|l|}{$\begin{array}{l}\text { Food-specific } \\
\text { discussion good }\end{array}$} & & & & 1 \\
\hline & \multicolumn{2}{|c|}{\begin{tabular}{l|} 
More food- \\
specific \\
discussion \\
wanted
\end{tabular}} & 1 & 1 & & 4 \\
\hline \multirow[t]{5}{*}{ Logistics } & \multicolumn{2}{|c|}{ Curriculum suggestion } & 1 & & 2 & 11 \\
\hline & \multicolumn{2}{|c|}{ More education wanted } & 3 & & 1 & 5 \\
\hline & \multicolumn{2}{|c|}{ More time wanted } & 1 & & & 12 \\
\hline & \multicolumn{2}{|c|}{ Safe space created } & & 1 & & \\
\hline & \multicolumn{2}{|c|}{$\begin{array}{l}\text { Suggestion for improvement } \\
\text { (general) }\end{array}$} & 2 & 1 & & 6 \\
\hline \multirow[t]{5}{*}{ Outcomes/Afterlife } & \multicolumn{2}{|c|}{$\begin{array}{l}\text { Applied/on-the-ground } \\
\text { visioning }\end{array}$} & 2 & 2 & 2 & 7 \\
\hline & \multicolumn{2}{|c|}{ Expanding reach } & 1 & & 1 & \\
\hline & \multicolumn{2}{|c|}{ Future-oriented visioning } & & & 3 & 12 \\
\hline & \multicolumn{2}{|c|}{ Motivation to act } & & & 1 & 8 \\
\hline & \multicolumn{2}{|c|}{ Professional relevancy } & 2 & & & 7 \\
\hline \multirow[t]{8}{*}{ Reactions } & \multicolumn{2}{|c|}{ Challenged by concepts } & & 1 & 1 & 3 \\
\hline & \multicolumn{2}{|c|}{$\begin{array}{l}\text { Concern for unrepresented } \\
\text { communities }\end{array}$} & & 2 & 1 & 8 \\
\hline & $\begin{array}{l}\text { Connecting cont } \\
\text { scales }\end{array}$ & t across & 1 & 5 & & 5 \\
\hline & Importance of w & & 1 & & & 13 \\
\hline & Introduced to ne & concepts & 2 & & & 12 \\
\hline & More diversity $n$ & ded & 1 & & 1 & 8 \\
\hline & Perceptions of ex & ertise & & & & 1 \\
\hline & Perceptions of re & esented & 2 & 3 & & 3 \\
\hline
\end{tabular}




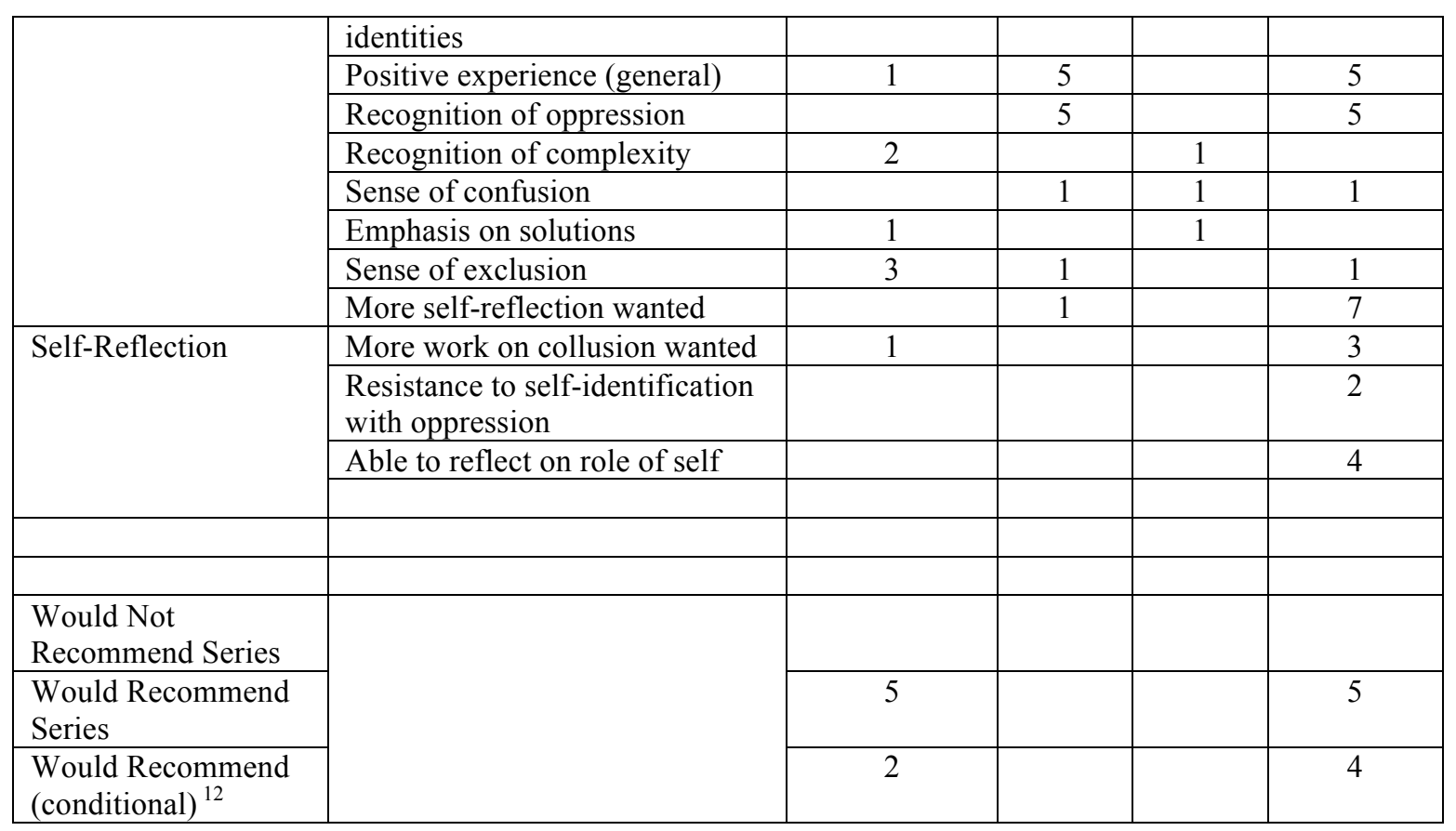

\footnotetext{
${ }^{12}$ The conditional component of this code meant any indication that the participant would recommend the series to others under the condition that some recommendation was met (i.e. the participation of more people of color).
} 